
2001.

\title{
EL PAPEL DE LAS FINANZAS EN LA DINÁMICA ECONÓMICA ARGENTINA ENTRE 1976 y 2001
}

\section{THE ROLE OF FINANCE IN ARGENTINEAN ECONOMIC DYNAMICS BETWEEN 1976 AND 2001}

\author{
MARISA BORDÓN \\ Universidad Complutense de Madrid \\ bordon_marisa@hotmail.com \\ Fecha recepción: 18 de noviembre de 2010 \\ Fecha aceptación: 9 de marzo de 2011 \\ doi: 10.5209/rev_PADE.2011.v22.5
}

\begin{abstract}
RESUMEN
A través de determinadas políticas económicas llevadas a cabo por los diferentes gobiernos desde 1976 a 2001, el capital financiero se convierte en el centro gravitatorio sobre el que se articula el modelo de acumulación en la Argentina, y esto se manifiesta, no sólo en términos cuantitativos en el crecimiento y dinamismo de la esfera financiera, sino en términos cualitativos, ya que contribuye a explicar los cambios que se producen en tres dimensiones: la estructura económica, la regresión social y la dependencia exterior. Los comportamientos del Estado, el sector no financiero, el sector financiero y el capital extranjero y sus interrelaciones configuran este nuevo papel de las finanzas en la dinámica económica.
\end{abstract}

PALABRAS CLAVES: modelo de acumulación, capital financiero, dinámica económica, políticas económicas.

JEL: E44, E52, E65, F34, O16,P43

\begin{abstract}
Through certain economic policies undertaken by different governments from 1976 to 2001, the financial capital becomes the center of gravity through which the model of accumulation in Argentina articulates itself. This can be seen in the growth and the dynamism of the financial sphere not only in quantitative, but also in qualitative terms because it helps to explain the changes that occur in three dimensions: economic structure, social decline and external dependence. The behavior of State, nonfinancial and financial sector, the foreign capital and their interrelationships constitutes this new role of finance in economic dynamics.
\end{abstract}

KEYWORDS: model of accumulation, financial capital, economic dynamics, economic policies. 
Bordón, Marisa. El papel de las finanzas en la dinámica económica argentina entre 1976 y 2001.

\section{INTRODUCCIÓN}

Las transformaciones sufridas en las economías desarrolladas tras el quiebre del modelo de acumulación mundial, a principios de los años 70 , han supuesto un giro radical, a partir del cual, los capitales centraron parte de su actividad en los circuitos financieros donde las expectativas de rentabilidad resultaron más elevadas. Dichas modificaciones implicaron que en las últimas décadas el capital financiero adquiriera protagonismo en el escenario mundial.

Las dificultades en las economías desarrolladas no tardaron en trasladarse a los países latinoamericanos, que abandonaron sus estrategias de crecimiento basadas en la industrialización por sustitución de importaciones (ISI) y engrosaron su deuda al absorber el exceso de liquidez que se generó por la crisis del centro y la subida del precio del petróleo.

En la Argentina los cambios en la dinámica económica comienzan a partir del gobierno militar de 1976. Las políticas económicas del nuevo gobierno dieron lugar a la configuración de un nuevo modelo de acumulación, en donde la esfera financiera parece colocarse en el centro de la escena dejando a un lado el antiguo modelo, en donde el crecimiento estaba basado en la industria, la participación de los trabajadores en el ingreso había aumentado, y el Estado impulsaba el desarrollo industrial (Basualdo, 2006).

Teniendo en cuenta estas transformaciones, el objeto de estudio de este trabajo es el comportamiento del capital financiero como rasgo relevante del modelo de acumulación vigente en la Argentina, desde 1976 hasta 2001, y lo que se pretende es ver si la dinámica financiera amplia su papel en ese nuevo modelo de acumulación, mediante el análisis de su lógica de funcionamiento y de la constatación del mismo a través de datos empíricos. No es la intención de este trabajo analizar los impactos que esta dinámica tiene en el ámbito social o en el amplio espectro económico, aunque algunos sean mencionados con el objeto de clarificar parte de las cuestiones planteadas.

La guía para dicho análisis surge de algunos conceptos teóricos y enfoques que se describen a continuación.

El concepto de modelos de acumulación que se utiliza en este trabajo es el de "formas simplificadas de representar las características de regularidad $y$ permanencia con respecto al modo en que los fenómenos se relacionan entre sí y con respecto a la forma en que se desarrollan en el tiempo", que permite " una visión consistente que explique simultáneamente los mecanismos de permanencia y de cambio de la dinámica capitalista" para mostrar "la lógica de acumulación y reproducción del sistema económico" (Palazuelos, 2002: 252). Se trata de una globalidad que se despliega en el tiempo cuyas partes integrantes- planos (estructuras económicas desarrolladas, subdesarrolladas e internacional), ámbitos (oferta, demanda, distribución de la renta, marco institucional y los correspondientes al plano internacional, flujos de intercambio de bienes, servicios, relaciones financieras, etc.), elementos y variables- se dotan de coherencia mediante relaciones de interdependencia que impulsan la dinámica de acumulación (Palazuelos, 2000). En este trabajo no se pretende hacer una descripción del modo 
Bordón, Marisa. El papel de las finanzas en la dinámica económica argentina entre 1976 y 2001.

de acumulación tal cual lo propone este esquema ya que hubiera excedido su extensión. No obstante, la descripción de los rasgos del modelo de acumulación en la Argentina presente en la segunda parte del trabajo está inspirada en esta visión.

El concepto de capital financiero que utilizamos es el que corresponde a Marx como fracción de capital que financia las actividades de producción y comercialización, pero que también realiza actividades especulativas en torno a ellas. En este sentido, Serfati dice que el capital financiero debe considerarse en dos dimensiones: una de ellas es la que se refiere a "los recursos que conservan la forma de dinero y que se valorizan en forma de dinero, convirtiéndose en capital, tomando la forma de créditos (préstamos y obligaciones), de derechos de propiedad (acciones) o de múltiples combinaciones de unos y otros"; y la otra engloba a entidades como bancos, aseguradoras, fondos de pensiones, cuyo cometido consiste en centralizar el dinero en forma de créditos o de derechos de propiedad para rentabilizarlo, y a los mercados financieros (Serfati, 2003: 59).

Desde la primera dimensión el capital financiero es dinero que se valoriza a sí mismo; sin pasar por la actividad productiva se convierte en una suma de dinero mayor (D-D'). Según Marx, hay etapas en las que las economías se ven atraídas por la sensación de que se puede generar dinero sin pasar por el proceso de producción (Serfati, 2003); la etapa que comienza a principios de los años 70 en los países desarrollados sería una de ellas. Al valorizarse a través de actividades desvinculadas de la actividad real, como la especulación bursátil, esta fracción de capital se vuelve relativamente autónoma. Aunque las acciones y obligaciones representen capital invertido en la empresa, son relativamente autónomas porque su valor no está en función del valor del capital real sino de las leyes que regulan los mercados financieros; está determinado por las expectativas de ganancias futuras. Es por eso que Marx lo llamaba capital "ficticio" (Gill, 2002). Sin embargo, aunque el capital financiero parece alimentarse a sí mismo, lo hace de la actividad real (Gill, 2002), participa de las ganancias por lo que es necesario que éstas se amplíen. Los intereses y dividendos que reciben los propietarios del capital financiero no proceden de la redistribución de los beneficios sino de la redistribución entre capital y trabajo (Serfati, 2003), convirtiendo a los salarios y al empleo en las variables de ajuste (Chesnais, 2001).

La relativa autonomía del capital financiero en las últimas décadas, ha provocado cambios en la estructura económica, en el comportamiento de las empresas y en las políticas económicas, que se convierten en conductos de la expansión de las finanzas. Estos conductos interactúan entre sí, la política económica influye sobre la estructura de los mercados financieros y el comportamiento de las empresas y, a su vez, las empresas y la esfera financiera adquieren capacidad para influir en la política económica (Palley, 2007) en la medida en que estos capitales son necesarios para la dinámica económica.

El capital financiero se consolida y mediante nuevas formas de gestión pone al proceso productivo en función de su lógica. Esto se consigue por los cambios institucionales de las políticas neoliberales (desregulación de mercados financieros, políticas monetarias favorables a los acreedores), tipos de interés elevados y el suministro de liquidez a los mercados. Los mercados financieros y los inversores institucionales (la segunda dimensión del capital financiero), determinan el horizonte 
Bordón, Marisa. El papel de las finanzas en la dinámica económica argentina entre 1976 y 2001.

de valorización del capital a favor de las rentabilidades a corto plazo, lo que afecta a la inversión productiva, a la producción y al empleo, ralentizando el crecimiento de la economía (Chesnais, 2001b).

Los países subdesarrollados se integran a la lógica financiera mundial a través de la absorción del exceso de liquidez, proveniente del comercio del petróleo de los países árabes, que fueron invertidos en activos 0 depositados en bancos internacionales y que, en plena recesión, las economías desarrolladas se dispusieron a rentabilizar mediante la concesión de grandes préstamos (Palazuelos, 2000). Este exceso de liquidez es el origen de la crisis de la deuda de estos países en los 80, que a su vez es el origen de las medidas de ajuste fondomonetaristas, que refuerza esta integración, permitiendo la recomposición de las condiciones de valorización de capital, a través de la ampliación de espacios de acumulación y ganancia, a costa del sector público (privatizaciones) y de la ruptura del marco regulatorio nacional (apertura y desregulación externa), y del ensanchamiento de los márgenes de ganancia (recortes sociales, desregulación laboral) (Arrizabalo, 1997).

La implementación de estas medidas genera una gran dependencia de los mercados internacionales de capital en los países donde se aplican, que obliga a mantener los tipos de interés elevados, lo que influye negativamente en los proyectos de inversión (más costosos y menos atractivos que las inversiones financieras), aumenta la fragilidad de los bancos y encarece considerablemente el servicio de la deuda pública, incrementando el déficit presupuestario. El diferencial de rentabilidad entre la inversión financiera y la productiva crece en detrimento de esta última e incita aún más a las empresas a financiarizar sus actividades (Salama, 2003) con efectos negativos en la producción y empleo.

Teniendo en cuenta las anteriores consideraciones definimos nuestra hipótesis de trabajo, que no busca su contrastación, a los efectos de este trabajo, sino que es utilizada como hilo conductor para la descripción de la dinámica económica argentina durante este periodo y cuya parte empírica se concentra en la última década del siglo. Dadas las modificaciones que surgen a principios de los 70 en la economía mundial y la alineación de la economía argentina mediante políticas económicas concretas, nuestra hipótesis de trabajo es que el capital financiero se convierte en el centro gravitatorio sobre el que se articula el modelo de acumulación en la Argentina a partir de 1976, y esto se manifiesta, no sólo en términos cuantitativos en el crecimiento y dinamismo de la esfera financiera, sino en términos cualitativos, ya que contribuye a explicar los cambios que se producen en tres dimensiones: la estructura económica, la regresión social y la dependencia exterior. La forma en que conduciremos nuestro análisis es la siguiente: en primer lugar describiremos las políticas gubernamentales desde 1976 hasta vísperas de la crisis en 2001, que desmantelaron la ISI configurando un modelo de acumulación alternativo, así como los rasgos principales de dicho modelo. En segundo lugar, se analizará el comportamiento de los sujetos que contribuyen a la expansión del capital financiero para finalmente describir la lógica de funcionamiento en la que se relacionan estos sujetos para configurar la creciente importancia de las finanzas en la economía argentina desde mediados de 1970 hasta 2001. 
Bordón, Marisa. El papel de las finanzas en la dinámica económica argentina entre 1976 y 2001.

\section{TRANSFORMACIÓN DEL MODELO DE ACUMULACIÓN EN LA ARGENTINA A PARTIR DE 1976}

Si bien la consolidación del modelo de acumulación en el que la apropiación de valor por el capital financiero adquiere importancia, se consolida en los años 90 con la aplicación y profundización de las medidas de ajuste estructural, su configuración no puede entenderse sin los acontecimientos políticos y económicos sucedidos una década y media antes, por lo que abordaremos el estudio de las políticas económicas desde entonces, dividiendo el periodo de estudio en distintas fases cuyos rasgos son distintos y obedecen a lo sucedido en la economía internacional y a la alineación que se produce en el ámbito interno de la economía argentina.

La primera fase está comprendida entre los años 1976 y 1983 coincidiendo con el gobierno militar. A mediados de los años 70 comenzaron a producirse cambios en la economía mundial que orientaron la evolución de la economía argentina, configurándose el fin del modelo de acumulación basado en la ISI para dar paso a otro modelo en el que las finanzas cobran importancia en la valorización de capitales.

En la segunda fase que va desde el fin de la dictadura hasta 1989 se conjugan un contexto externo desfavorable, la situación crítica dejada por la dictadura militar y la importancia creciente de la esfera financiera, y se caracteriza por las restricciones externas y el intento por parte del gobierno de retomar las políticas de la ISI.

Finalmente, la tercera fase del estudio de las políticas económicas es la que ocupa la década de los 90, en donde las medidas de ajuste neoliberales, en el marco de la renegociación de la deuda externa, sientan las bases para el auge y la crisis del modelo.

En el siguiente apartado se presentará un esquema breve de las políticas económicas de cada fase sobre las que se basan los cambios principales que configuran el nuevo modelo de acumulación.

\subsection{Marco general de políticas económicas por periodo}

\subsubsection{6-1983. Desmantelamiento de la ISI e imposición de medidas fondomonetaristas}

En los años 70 la crisis de los países desarrollados, que se genera como consecuencia del agotamiento del modelo de acumulación fordista, va configurando cambios en la economía internacional, a los que la economía argentina se irá alineando. La caída de la tasa de ganancia afectaba a los niveles de inversión y de empleo y las políticas contractivas (para frenar la inflación) desincentivaban a los capitales industriales, que veían más atractivo trasladar sus recursos al circuito financiero. De esta forma, las actividades especulativas iban adquiriendo importancia, detrayendo recursos a la actividad productiva y convirtiéndose en uno de los elementos que disparaba la liquidez internacional (Arrizabalo, 1997). En este sentido, la subida de los precios del petróleo y los desequilibrios del comercio exterior norteamericano fueron elementos fundamentales para este exceso de 
Bordón, Marisa. El papel de las finanzas en la dinámica económica argentina entre 1976 y 2001.

liquidez, que financiará a los gobiernos de los países subdesarrollados, introduciéndolos en los circuitos financieros internacionales.

Tras un golpe de Estado, el 24 de Marzo de 1976, la Junta Militar, con Jorge R. Videla como presidente, toma el poder con el objetivo de actuar sobre "el desorden económico y político reinante" a través del proceso de "Reorganización Nacional". En el plano económico este proceso estaba encaminado a detener la inflación y reducir la intervención del Estado para controlar el déficit público y permitir al mercado asignar recursos más eficientemente. Sin embargo, el alcance de dichas políticas superaba ambos objetivos, ya que a la luz de lo sucedido puede apreciarse una clara intención de reestructurar la economía y la sociedad.

Una de las reformas más importantes del periodo es la financiera de 1977 basada en la ley 21.495 que permite la descentralización de los depósitos, y la ley 21.526 que trata sobre el nuevo régimen de entidades financieras ${ }^{1}$. Con dicha reforma se esperaba aumentar las colocaciones en activos financieros cuasi-líquidos para liberar la presión sobre el mercado de bienes y que estos ahorros financieros se vincularan con la inversión productiva.

Estas leyes ponen fin a 3 rasgos sobre los que se fundamentaba el sistema financiero en el anterior modelo: la nacionalización de los depósitos por parte del Banco Central de la República Argentina (BCRA) ${ }^{2}$, el control de la tasa de interés por esta entidad (se liberalizan los criterios de los bancos en la fijación de la tasa de interés nominal) y la escasa accesibilidad al crédito exterior del sector privado. El nuevo régimen de entidades financieras permitía la expansión de entidades ya existentes (a través de la participación accionarial en otras), la apertura de nueva entidades nacionales y extranjeras, y recrea la figura de prestamista de última instancia del BCRA (Basualdo, 2006).

El sistema financiero va dejando de lado su función subordinada a las necesidades de la economía real, ya que durante décadas había sido utilizado como mecanismo de transferencia de ingresos al servicio de la estrategia de industrialización.

Como consecuencia directa de estas medidas crecen los tipos de interés, aunque más factores influyeron en que se mantuvieran elevados e incluso creciera más durante todo el periodo, entre ellos la inflación y la amenaza de devaluación. Al final del periodo militar eran tales los desequilibrios y la dependencia de los capitales extranjeros que la tasa de interés se aumentaba con el fin de evitar una fuga financiera.

La reforma financiera se complementó con medidas de estabilización que también buscaban frenar la inflación, pero ni la "tregua de precios" ni las políticas restrictivas de oferta monetaria, alcanzaron el éxito esperado, ya sea por el efecto de los costes financieros a causa de la elevada tasa de interés, que afectaba los precios relativos, o por la entrada de liquidez procedente del exterior, por la misma causa.

\footnotetext{
${ }^{1}$ Un análisis más completo de la reforma financiera puede encontrarse en "Desarrollo reciente del mercado de capitales en la Argentina" de Roberto Frenkel (1980)

${ }^{2}$ Se reemplaza el sistema en el que las reservas representaban el $100 \%$ de los depósitos por otro de reservas fraccionarias $(45 \%)$ remuneradas.
} 
Bordón, Marisa. El papel de las finanzas en la dinámica económica argentina entre 1976 y 2001.

En 1979 se optó por la apertura comercial ${ }^{3}$ para controlar la inflación forzando a reducir los precios para competir con los productos extranjeros.

Las medidas de estabilización, la apertura comercial y financiera y la reforma del sistema financiero se articulaban en función del giro de la valorización del capital del ámbito real al financiero. La estabilización buscaba favorecer la entrada de capitales impidiendo que la elevada tasa de interés interna se viese mermada por los efectos de la inflación. La apertura comercial y financiera permitía la reestructuración económica en contra de los sectores industriales (no relacionados con la base social del nuevo régimen) y el libre flujo de capitales que, a su vez, posibilitaba dos cosas: el equilibrio de la balanza de pagos (perjudicada por la apertura comercial que eleva las importaciones y desincentiva la exportaciones) y el endeudamiento público y privado con el exterior (como ya veremos base fundamental para el nuevo modelo). La reforma financiera facilitaba que el sistema financiero se convirtiera en el eje del proceso modificando las condiciones de rentabilidad a favor de la valorización especulativa y en contra de los sectores productivos, que cada vez tenían más dificultades para financiarse ${ }^{4}$.

Además de aplicar estas medidas, el papel del Estado fue fundamental por su doctrina represiva que hizo viable la instauración de este modelo a través de la persecución y desaparición de individuos, y a través de su acción contra los organismos sociales, especialmente los que tenían que ver con la organización de los trabajadores ${ }^{5}$. También intervino en el proceso a través de su endeudamiento externo, fundamental para el ingreso de divisas necesarias para transferir al exterior el capital valorizado internamente, transfiriendo recursos a las fracciones dominantes de capital a través de la sobrevaloración de precios de compra de bienes y servicios y de planes de promoción industrial, y mediante la estatización de deuda privada en los últimos años de gobierno ${ }^{6}$. Pero el ámbito más relevante en donde el Estado manifiesta la convalidación de la valorización financiera de una parte del excedente del capital oligopólico es su capacidad, a pesar de la reforma financiera, para la conformación de la tasa de interés interna, del coste del endeudamiento con el exterior y, por lo tanto, del diferencial con la tasa de interés internacional (Basualdo, 2006). Si bien intentaba alinearse con las tendencias poco intervencionistas $y$ liberalizadoras del contexto internacional, el Estado sigue interviniendo aunque de una forma diferente que en el modelo ISI.

La dictadura instaura forzosamente un nuevo modelo de acumulación acorde a las tendencias internacionales, en el cual parte del capital se valoriza sin necesidad de las relaciones sociales con el trabajo presentes en el proceso productivo. Las políticas económicas de la época están dirigidas a reestructurar la economía

\footnotetext{
${ }^{3}$ Esta política no se impuso de manera homogénea en todos los sectores, algunas excepciones son la industria automotriz y siderúrgica. Esta medida se tomó junto con una devaluación monetaria progresiva, que no haría más que sobrevaluar la moneda retardando la caída de su valor.

${ }^{4}$ Las empresas oligopólicas pertenecientes a los grupos económicos locales o capitales extranjeros tenían acceso al crédito externo.

${ }^{5}$ Para más información consultar "Historia económica, política y social de la Argentina (1880-2000)" de Mario Rapoport (2000).

${ }^{6}$ Se otorgaron seguros de cambio y subsidios para compensar las fuertes devaluaciones producidas al final del periodo. En 1982 se estatiza la deuda externa privada, refinanciándose con títulos públicos. Para un tratamiento más profundo del tema consultar "Deuda externa y poder económico en la Argentina" de Eduardo Basualdo (1987).
} 
Bordón, Marisa. El papel de las finanzas en la dinámica económica argentina entre 1976 y 2001.

argentina haciendo perder peso a la industria. Con ello se consigue debilitar a la clase trabajadora (ya debilitada por la represión de sus organizaciones) por sus efectos negativos en el empleo, lo que sumado a las reformas en la legislación laboral da como resultado la disminución de los salarios reales y la reducción de la participación de los mismos en la renta nacional, favoreciendo así, la ampliación de los beneficios de los que se nutre la actividad financiera ${ }^{7}$.

Si bien no se logran los objetivos perseguidos por las políticas económicas (control de la inflación, más del $400 \%$, y del déficit público, 16,52\% del PIB), se consigue el que subyace en todas ellas: el giro hacia un nuevo modelo de acumulación en donde se amplían las ganancias de determinadas fracciones de capital a costa de reducir la parte de ingresos correspondiente a los trabajadores (durante este periodo dejan de percibir una cifra equivalente a 13 puntos porcentuales del PIB) y de nuevos espacios de valorización (sistema financiero).

\subsubsection{3-1989 Primer gobierno constitucional}

La década del 70 termina con el cambio de política monetaria por parte de la Reserva Federal, que elevará los tipos de interés afectando seriamente a los países endeudados en dólares y a tipos variables. Por otro lado, se deterioraron los términos de intercambio entre países industrializados y no industrializados limitando las fuentes de divisas necesarias para el pago de la deuda de estos últimos.

Ante esta situación se produce el cese de pagos que comienza en México en 1982 y al que le siguen otros países. A partir de entonces, con la intermediación del Fondo Monetario Internacional (FMI) y el Banco Mundial (BM), se establece un mecanismo de continuidad de pago de los intereses para lo cual los países subdesarrollados, más vulnerables a la coyuntura internacional por su gran endeudamiento, deberían sacrificar recursos fiscales e implementar medidas de ajuste, que condicionarían las nuevas financiaciones (Rapoport, 2000) y que se enmarcaban en la llamada "revolución neoliberal".

El 10 de diciembre de 1983 Raúl Alfonsín llega al poder cuando el país se encontraba en plena recesión con un desempleo creciente, una inflación de más del $400 \%$, la deuda externa de 45.000 millones de dólares, sin reservas internacionales y un gran déficit fiscal (Rapoport, 2000).

Las políticas económicas de la década tenían como objetivos prioritarios la recuperación del crecimiento económico, el control de la inflación y el pago de la deuda externa. Se centraron en la recuperación de la demanda interna mediante el aumento de los salarios reales, que estimularía la producción y a su vez la inversión, utilizando complementariamente diversas políticas de promoción industrial, así como nuevos mecanismos de estatización de deuda privada ${ }^{8}$. Pero el gobierno no tuvo en

\footnotetext{
${ }^{7}$ Durante la primera etapa del gobierno militar se congelan los salarios, como medida contra la inflación, se disuelve la CGT y se elimina el derecho a huelga.

${ }^{8}$ Se otorgaron recursos a través de los precios de transferencia, avalando deuda privada que nunca se pagaba, remunerando reservas a bancos privados y dando subsidios para evitar la quiebra de dichos bancos, que junto con la estatización de de deuda favorecen claramente a una fracción de capital formada por los grupos económicos locales y los capitales extranjeros presentes en el país desde la segunda fase del ISI
} 
Bordón, Marisa. El papel de las finanzas en la dinámica económica argentina entre 1976 y 2001.

cuenta la pérdida de vigencia del modelo de acumulación anterior y lo cambios profundos que se habían producido en la estructura económica argentina, por lo que si bien en un comienzo las medidas elevaron el consumo, los efectos en la inversión fueron modestos por el desvío de recursos al sistema especulativo.

La promoción industrial contribuyó a empeorar el déficit fiscal al aumentar el gasto, ya que no se consigue reactivar la economía y la recaudación. Tampoco se tomaron medidas para frenar la fuga de capitales, elemento fundamental para el nuevo modelo.

En 1985 el Plan Austral surge como un intento de dar solución a la hiperinflación y al pago de la deuda externa; se congelan todos los precios, aumentan las retenciones a las exportaciones, cambia el signo monetario, se impide que el BCRA emita dinero para financiar el déficit fiscal, se reduce el tipo de interés y se aplica un "ahorro forzoso" a los sectores de mayor ingreso (Basualdo, 2006). A pesar de los numerosos ajustes que se realizaron al plan, ninguno tuvo incidencia en la dramática situación del país, hacia 1987 el desempleo era del 6,5\%, la deuda externa ascendía a 51.000 millones de dólares y la recesión comenzaba a sentirse.

Las políticas de la época tampoco fueron efectivas en términos de control inflacionario, lo que se explica por varios factores. Por un lado los intentos de restricción monetaria chocaban con la necesidad de comprar divisas del gobierno para cancelar sus obligaciones con el exterior, lo que terminaba por inyectar liquidez. Se intentaba, entonces, esterilizar el dinero inyectado a través de títulos de deuda pública, que elevaban el tipo de interés progresivamente en la medida en que se saturaba el mercado y era necesario mantener el atractivo de los bonos. El aumento del tipo de interés nominal elevaba la inflación que, a su vez, elevaba nuevamente los tipos.

Por otro lado, el conflicto creciente entre dos fracciones de capital, por un lado los grupos económicos y empresas extranjeras, beneficiadas, en cierta medida, por la política del Estado y por el otro, los acreedores externos, perjudicados por los continuos ceses de pago, también influían en el proceso inflacionario ${ }^{9}$.

En 1988 el Congreso veta los primeros intentos de privatización y el país entra en "moratoria de hecho" del pago de intereses de la deuda externa. El plan primavera es el último intento para evitar el colapso de la economía, destacándose entre sus medidas, la liberalización del tipo de interés interno, impulsada por la deuda del sector público a corto plazo, que genera una entrada masiva de capitales al país.

En 1989 el BM informa que no realizará los desembolsos previstos, se produce una devaluación de la moneda del $180 \%$ y una crecida equivalente de la tasa de inflación, generando una salida masiva de capitales. Se adelantan las elecciones y el partido justicialista llega al poder iniciando la fase donde las medidas neoliberales rematarán el trabajo comenzado por la junta militar a mediados del 70.

\footnotetext{
${ }^{9}$ También contribuía al aumento de precios el hecho de que las empresas oligopólicas, que habían comenzado estrategias de integración vertical y horizontal en la década anterior, subieran los precios a pesar de las medidas de control impuestas, alegando aumento de costes.
} 
Bordón, Marisa. El papel de las finanzas en la dinámica económica argentina entre 1976 y 2001.

Las medidas tomadas por el gobierno no consideran los cambios acaecidos en la etapa anterior por lo que no logran los objetivos de reactivar el crecimiento y superar sus problemas con el pago de las obligaciones internacionales. Por otro lado, aunque el acceso a capitales extranjeros es limitado, el modelo de acumulación instaurado en la fase anterior continua funcionando gracias a dos elementos: los elevados tipos de interés, resultado de las políticas de control de inflación y de las necesidades de financiación del sector público, y las políticas de incentivos, fuente de fondos susceptibles de ingresar en el circuito financiero.

\subsubsection{0-2001. Consolidación del nuevo modelo de acumulación}

Las políticas macroeconómicas del gobierno de Carlos Menem (1989-1999) para hacer frente al escenario de crisis generado por la hiperinflación, el déficit fiscal, el desequilibrio en la balanza de pagos y la recesión económica, están marcadas por las condiciones de los organismos internacionales para la renegociación de la deuda externa, cuyo pago es suspendido en la etapa anterior. Es conveniente aclarar que aunque el periodo se extiende hasta el 2001, nos centramos sólo en el gobierno justicialista por concentrar los lineamientos de política económica más relevantes a efectos de este trabajo.

A través de las leyes de Reforma del Estado (23.696) y Emergencia Económica (23.697) se marcan los ejes estratégicos de la política económica, se autoriza la privatización de casi todas las empresas públicas, la suspensión de subsidios, la eliminación del sistema "compre nacional"10, se da autonomía al BCRA y se liberalizan las inversiones extranjeras.

El Plan de convertibilidad llega a comienzos de 1990 como una de las piedras angulares de la estrategia con el objetivo de estabilizar los precios al largo plazo y alentar el ingreso masivo de capitales extranjeros por el atractivo de los altos tipos de interés y las altas tasas de ganancia (Neffa, 1998). Las otras dos piedras angulares son la apertura comercial, que intenta disciplinar los precios internos y aumentar la productividad a través de la competencia extranjera, y las privatizaciones, que según el discurso oficial, buscan sanear las cuentas públicas y aumentar la eficiencia y calidad de los servicios.

El Plan establecía un tipo de cambio fijo, donde un dólar era igual a un peso, y con el $100 \%$ de reservas respaldando la emisión. El primer perjudicado fue el sector productivo, por la pérdida de competitividad en las exportaciones y la entrada de importaciones baratas. Sin embargo frenó la inflación y permitió la estabilidad requerida para la entrada de capitales que compensaría el déficit de la cuenta corriente (provocado por la sobrevaluación de la moneda). Por otro lado, el Estado perdió la posibilidad de devaluar la moneda y de utilizar la política monetaria a través de la contracción o relajación de la oferta de dinero.

La apertura comercial, más que contribuir a estabilizar los precios, acabó con el resto de las industrias que habían sobrevivido a la liberalización de mediados de los 70 y a los desequilibrios de los 80. La apertura financiera facilitaba la entrada de

\footnotetext{
${ }^{10}$ Según esta ley en las compras del Estado tienen preferencia los bienes y servicios de empresas nacionales.
} 
Bordón, Marisa. El papel de las finanzas en la dinámica económica argentina entre 1976 y 2001.

capitales dirigidos a la adquisición y concesión de empresas estatales promovida por las privatizaciones y a demás inversiones especulativas.

En 1990 se producen las primeras privatizaciones favoreciendo a empresas transnacionales, bancos extranjeros y grupos económicos locales ${ }^{11}$. Este proceso tiene importancia en tres aspectos: el primero es la transformación estructural a la que contribuye, el segundo la transferencia de recursos a los sectores dominantes, y el tercero es su papel en la valorización financiera de capitales, en la medida en que la venta de las participaciones de los grupos económicos locales, a mediados de la década, se convierten en fondos susceptibles de ingresar al circuito financiero, valorizarse y salir del país ${ }^{12}$. Aunque las privatizaciones no consiguen al $100 \%$ ninguno de sus objetivos supuestos, ya que el equilibrio de las cuentas fiscales será temporal y los logros en términos de calidad dudosos, si consiguen los objetivos subyacentes: uno, resolver el conflicto entre acreedores externos, que capitalizaron su deuda, y los grupos económicos locales y conglomerados extranjeros, que a cambio de las prebendas del Estado se convirtieron en propietarias (Azpiazu y Basualdo, 2004); dos, el Estado dejó de tener influencia en la economía a través de las empresas públicas.

Complementando lo anterior, la desregulación del mercado laboral se llevó adelante para aumentar la competitividad a través de la reducción de costes laborales. A cambio los trabajadores perdieron participación en la renta nacional y se redujo el salario real por la presión del desempleo (ya existente pero acentuado por el cierre de numerosas empresas y de la expulsión de fuerza de trabajo de las privatizadas) y por la reducción de los salarios indirectos como consecuencia de la pérdida de derechos, de la subida de las tarifas de los servicios públicos y de la privatización del sistema de pensiones ${ }^{13}$.

A pesar de que durante la última década y media el Estado había permitido a través de sus políticas, una redistribución a favor de las fracciones de capital dominantes, la situación de déficit fiscal debida a la presión de la deuda externa impedía que se completara el circuito de valorización financiera a través del ingreso de divisas y la fuga de capitales (circuito del que se hablará en detalle más adelante en este trabajo) e imposibilitaba el pago de intereses a los tenedores de deuda externa (Rapoport, 2000).

\footnotetext{
${ }^{11}$ Los consorcios debían estar formados por estos tres tipos de empresas (Kulfas, Porta y Ramos, 2002).

${ }_{12}$ El alcance de las privatizaciones a una amplia gama de actividades es lo que determina su importancia en la transformación estructural de la economía. También afectan al sistema productivo por el aumento de las tarifas por parte de los consorcios propietarios, que eleva los costes y perjudica la competitividad, y por el cierre de empresas locales que pierden a su principal cliente: el Estado. Por otro lado, las privatizaciones dan acceso a enormes mercados cautivos con ganancias garantizadas, que se complementan con numerosas concesiones que favorecieron enormemente a las empresas participantes particulares del proceso argentino. Para más información consultar "Las privatizaciones en la Argentina. Génesis, desarrollo y principales impactos estructurales" de Daniel Azpiazu y Eduardo Basualdo (2004)

${ }^{13}$ Se eliminó la indexación de los salarios, vinculando su evolución a la productividad, se limitó el derecho a huelga, se descentralizaron las negociaciones colectivas, se instauraron nuevas formas de contrato temporal, se redujeron los aporte patronales y las asignaciones familiares y se redujeron las indemnizaciones por despido (Basualdo, 2006)
} 
Bordón, Marisa. El papel de las finanzas en la dinámica económica argentina entre 1976 y 2001.

Por eso todas estas medidas tienen como objetivo retirar al Estado de la actividad económica, realizando una importante transferencia de fondos y ampliando los espacios de ganancia de las fracciones de capital dominantes, consolidando el modelo en el que el capital financiero cobra importancia. No obstante, estas políticas vuelven más vulnerable a la economía por las contradicciones que se generan en su interior. La necesidad de divisas para el pago de la deuda y para mantener la paridad obliga a una entrada continua de capitales. Pero la salidas de capitales aumentan por la repatriación de beneficios de empresas privatizadas, las transferencias a través de operaciones intrafirmas y la fuga de capitales propias del modelo; y el déficit de la balanza de pagos empeora por el desequilibrio de la balanza por cuenta corriente provocado por la política cambiaria y comercial. Esta situación no podrá mantenerse, son los mismos lineamientos económicos que buscan consolidar el modelo de acumulación los que generan las condiciones para su crisis.

\subsection{Caracterización del nuevo modelo de acumulación}

La interacción de los diferentes elementos aportados en cada fase deja como resultado una economía con unos rasgos determinados que dan forma al nuevo modelo de acumulación en donde la valorización de capital en el ámbito financiero cobra una importancia fundamental.

a) Economía desindustrializada:

El alejamiento del sistema financiero como instrumento al servicio del aparato productivo, las medidas de liberalización y el encarecimiento del crédito son los primeros pasos que se dan durante el proceso militar de 1976 y que implican una reducción de los sectores productivos en la economía, que se cristaliza en la reducción de unidades productivas y de puestos de trabajo en el sector manufacturero, de acuerdo a los datos de la tabla 1.

Tabla 1. Número de industrias y puestos de trabajo sector manufacturero

\begin{tabular}{|c|c|c|c|c|c|c|c|}
\hline \multicolumn{4}{|c|}{ Unidades censales productivas } & \multicolumn{4}{c|}{ Puestos de trabajo ocupados } \\
\hline 1974 & 1985 & 1994 & 2003 & 1974 & 1985 & 1994 & 2003 \\
\hline 126.388 & 109.376 & 101.524 & 84.971 & 1.525 .221 & 1.381 .805 & 1.058 .379 & 952.911 \\
\hline
\end{tabular}

El golpe definitivo se da con las políticas de de liberalización comercial y las privatizaciones en la década del 90. La apertura comercial provoca el cierre de numerosas empresas que no pueden hacer frente a los precios, la calidad y variedad de los productos extranjeros. Las privatizaciones, por las características del proceso, contribuyen a la concentración y centralización de capital, así como al aumento de la presencia de propietarios extranjeros en la economía. Estas tendencias se acentuarán con el aumento de las fusiones y adquisiciones de éstas y otras empresas, en la segunda mitad de la década.

En cuanto a la reestructuración del sector, la apertura asimétrica contribuyó a la "desintegración" de la producción local, que convierte a numerosas industrias, como la automotriz, en simples ensambladoras de insumos y partes importadas, mientras 
Bordón, Marisa. El papel de las finanzas en la dinámica económica argentina entre 1976 y 2001.

que otras se transforman en empresas comerciales, como es el caso de las especializadas en electrodomésticos y otros bienes durables (Basualdo, 2006).

El sector productivo también estuvo expuesto a los efectos de las diferentes medidas que reducían los salarios y precarizan el trabajo afectando a la demanda interna, que volvía a impactar en las inversiones y en la producción. A su vez, la reestructuración sectorial reforzaba los efectos de estas medidas con la expulsión de mano de obra que contribuía a la reducción del salario real.

A partir de todos estos elementos el resultado es una creciente heterogeneidad estructural en donde existen industrias muy desarrolladas (principalmente las vinculadas a los recursos naturales y exportación) pero que no crean empleo y poco vinculadas con el resto de la economía, frente a otro sector industrial poco desarrollado en comparación con los niveles internacionales, generalmente orientado al mercado interno ${ }^{14}$.

Esto se manifiesta en una caída de la participación de la industria en el PIB, que según la encuesta de 2004/2005 del INDEC era de casi el $20 \%$ en 1980 y del 13,6\% en 2001 , al igual que su valor agregado, que pasa del $20 \%$ del valor agregado total en 1990 al $17 \%$ en 2001.

b) Mercados financieros ampliados pero dependientes de la evolución de los mercados internacionales:

A partir de la Reforma de 1977 el sistema financiero se libera del control del Estado, se produce un aumento del número de entidades financieras y el mercado financiero se convierte en un mercado de bonos en el corto plazo. La apertura financiera de 1976 convirtió a la economía argentina en una economía de libre movimiento de capitales, en donde el crédito externo es fundamental para la oferta de crédito y la determinación del tipo de interés (Frenkel, 1980).

La emisión de deuda pública, los elevados tipos de interés, las condiciones fiscales favorables y la libertad de movimiento de capitales otorgaron dinamismo al sector durante las dos décadas y media de vigencia del nuevo modelo.

Durante la última fase se favoreció la concentración y desnacionalización de la banca, especialmente después de la crisis provocada por el "efecto tequila" en 1995. El sistema financiero se caracterizó por el origen foráneo de sus capitales y de sus entidades financieras y por su fragilidad.

El dinamismo de las finanzas también se vio favorecido por las privatizaciones a través de dos elementos. Por un lado la privatización del sistema de pensiones liberó recursos que reactivaron los mercados y las Administradoras de fondos de jubilaciones y pensiones (AFJP) se convirtieron en financiadoras del Estado; por ley se les obligaba a destinar un $50 \%$ de sus recursos a inversiones en títulos públicos

\footnotetext{
${ }^{14}$ Adquieren importancia las actividades sustentadas en ventajas comparativas naturales (alimentos, bebidas, refinación de petróleo e industria petroquímica, celulosa y papel) y las industrias protegidas por regímenes excepcionales como la automotriz. Todas ellas oligopólicas con el $65 \%$ de la producción y el $75 \%$ de las exportaciones durante la década del 90. En contraposición las industrias textil y de confección pierden importancia en el PIB por la caída de la demanda interna, al igual que las productoras de bienes de capital por ser incapaces de competir con la importación.
} 
Bordón, Marisa. El papel de las finanzas en la dinámica económica argentina entre 1976 y 2001.

nacionales (Neffa, 1998). Por el otro, las privatizaciones (aunque no exclusivamente) cumplen un rol fundamental en la conversión de empresas en activos financieros, que permiten obtener rentas patrimoniales a través de su enajenación (Basualdo, 2009).

Este apartado será ampliado en la tercera parte de este trabajo del que constituye su "objeto específico".

c) Inserción Externa dependiente:

Las modificaciones en el ámbito productivo, las políticas económicas que se han aplicado a lo largo de estos años y la necesidad de divisas para el pago de la deuda externa van configurando una inserción externa caracterizada por la dependencia. En primer lugar, hay una tendencia hacia las exportaciones vinculadas a recursos naturales y en el caso de la exportación de manufacturas adquieren importancia los insumos y productos como aceites vegetales y pasta de papel, con escaso valor añadido. Esto es relevante por la volatilidad de los precios internacionales de estos bienes. Observamos en la tabla 2 que después de dos décadas, las manufacturas de origen industrial disminuyen su participación, aunque levemente, en el total de exportaciones. En la década del 90 hay un aumento considerable de las manufacturas en general, en el 2001 la tendencia se revierte a favor de los productos primarios y los recursos energéticos principalmente.

Tabla 2. Porcentaje de Exportaciones por Grandes rubros

\begin{tabular}{|l|c|c|c|}
\hline \multirow{2}{*}{\multicolumn{1}{|c|}{ Rubros }} & \multicolumn{3}{c|}{ Años } \\
\cline { 2 - 4 } & $\mathbf{1 9 8 0}$ & $\mathbf{1 9 9 0}$ & $\mathbf{2 0 0 1}$ \\
\hline Productos primarios & $36,95 \%$ & $20,44 \%$ & $22,80 \%$ \\
Manufacturas de origen agropecuario & $40,31 \%$ & $42,72 \%$ & $28,11 \%$ \\
Manufacturas de origen industrial & $19,26 \%$ & $33,26 \%$ & $31,29 \%$ \\
Combustibles y energía & $3 \%$ & $4 \%$ & $18 \%$ \\
\hline
\end{tabular}

La reducción de la demanda interna consolidó la tendencia exportadora, el incremento del PIB no se buscaba a través de la producción nacional y el consumo masivo de bienes durables.

Las importaciones de bienes de capital y equipos adquirieron importancia en la medida en que eran más competitivos que los producidos en el país, en términos de precio y tecnología. Por otro lado, el aumento de las empresas en manos de capitales extranjeros contribuyó a consolidar esta tendencia importadora.

En segundo lugar, durante la última fase en la que tuvo vigencia el modelo de acumulación que reemplazó al ISI se produjo un ingreso masivo de capitales, no sólo especulativos sino los destinados a inversión extranjera directa (IED), atraídos principalmente por las privatizaciones. Según datos del Ministerio de Economía de la Nación (MECON), ingresan 76.440 millones de dólares en concepto de IED entre 1992 y 2001. 
Bordón, Marisa. El papel de las finanzas en la dinámica económica argentina entre 1976 y 2001.

La paridad fija de la moneda nacional al dólar y las características de los precios de las exportaciones (que le aportan inestabilidad) afectan negativamente a la balanza por cuenta corriente, lo que dificulta la obtención de divisas por la vía comercial. Se genera así una dependencia hacia los capitales extranjeros que estabilizan la balanza de pagos y permiten el funcionamiento del modelo de acumulación donde las finanzas adquieren importancia.

d) Papel del Estado: reducción y reorientación de la intervención:

El papel del Estado se modifica cuando deja de tener al sistema financiero como herramienta de redistribución, como resultado de la reforma financiera, aunque sigue interviniendo en la economía, tal como hemos visto, hasta finales de los años 80 . En la década del 90 pierde su capacidad de intervenir a través de las empresas estatales y de la política monetaria. Se convierte en un Estado débil en la medida en que se reducen sus fuentes de ingresos como consecuencia de la privatización de las empresas públicas y del sistema de pensiones, y del aumento de las obligaciones en el marco de las negociaciones del Plan Brady (la deuda supera los 140.000 millones de dólares, el 57\% del PIB, en 2001). La deuda limita su capacidad de acción, por restringir su solvencia y por los condicionamientos de los organismos internacionales en términos de política económica.

Esta reorientación del Estado que se caracteriza por el déficit y la deuda externa tiene como efecto una redistribución regresiva, no hacia las clases más bajas, sino hacia las fracciones de capital dominantes, y es desde aquí donde puede cuestionarse su capacidad de intervención. Esto resulta muy importante porque el coste de la deuda y la quiebra del Estado serán asumidos por la masa de población que, en ningún caso, se ha beneficiado de esta situación.

e) Distribución de la renta y polarización social:

Uno de los principales efectos de la configuración del nuevo modelo de acumulación fue la redistribución de la renta a favor del capital y en contra del salario. Tal como hemos visto, gracias a los cambios estructurales de la economía, los procesos inflacionarios y de crisis y a las diferentes reformas laborales, el salario perdió participación en la renta, pasando de representar el 45\% en 1974, el 32\% en 1990 (Neffa, 1998), y el 28\% en 2001 (Basualdo, 2006). Por otro lado, el desempleo aumentó, según datos del INDEC, del $5 \%$ en mayo de 1974 , al $16 \%$ en Mayo de 2001. El aumento del desempleo, la precarización del trabajo y la disminución del salario real tienen como consecuencia un aumento de la desigualdad, la pobreza, la marginación y la exclusión social ${ }^{15}$.

Hasta aquí, la caracterización del modelo de acumulación que surge en Argentina en el periodo estudiado, a través de estos 5 rasgos: la desindustrialización, el mayor peso y dependencia externa de las finanzas, la mayor importancia del capital extranjero y la vuelta del comercio exterior a una tendencia primario-exportadora, la reorientación y recorte del Estado, y la polarización social. Los mismos se han seleccionado ya que su conocimiento es fundamental a efectos de nuestro análisis; comprendemos que una explicación más detallada de todos sus elementos hubiera excedido la finalidad de este trabajo.

15 En 1980 el quintil más pobre tenía el 2,8 \% de los ingresos y el quintil más rico el 30,9\%, para pasar en 1999 a 1,3\% y 43,1\%, respectivamente y llegar finalmente a un mínimo en 2002 del 0,8\% y 47,3\% (nivel similar a Brasil y Chile)- Fuente anuarios CEPAL 2000 y 2009. 
Bordón, Marisa. El papel de las finanzas en la dinámica económica argentina entre 1976 y 2001.

\section{EL PAPEL DE LAS FINANZAS EN EL NUEVO MODELO DE ACMULACIÓN}

En este apartado abordaremos el análisis de los sujetos que participan activamente en la lógica del modelo de acumulación donde la esfera financiera cobra importancia, durante su fase de consolidación entre 1990 y 2001, para luego dar una visión integrada de todos ellos en la lógica de funcionamiento del modelo. El análisis no incluye el periodo inmediatamente posterior debido a que se han producido algunos cambios que, sin ser radicales, nos hacen pensar que no se trata de la misma dinámica económica que la predecesora.

\subsection{Sujetos participantes en la expansión de las finanzas}

\subsubsection{El Estado creador de las condiciones y potenciador del proceso}

Como se ha dejado ver en el apartado anterior, el Estado cumple un papel fundamental en el proceso puesto que configura las políticas económicas que generan las condiciones adecuadas para el surgimiento del modelo de acumulación con una mayor participación de las finanzas.

Pero no sólo genera las condiciones, sino que participa dentro de la lógica del nuevo modelo a través de dos elementos que se desprenden de su necesidad de financiación y que son fundamentales para dinamizar el proceso. Por un lado mantiene elevados los tipos de interés ${ }^{16}$, lo que aumenta las rentabilidades en el ámbito financiero, y por el otro, alimenta al mercado con la emisión de títulos de deuda pública.

Durante los primeros años del gobierno de Carlos Menem hubo superávit público debido a la mejora de la capacidad recaudatoria, resultado de cierta recuperación económica y a la entrada de recursos proveniente de las privatizaciones. Por su parte, la deuda externa pública (el mayor componente de la deuda total) se redujo por el rescate de títulos a través de las privatizaciones (7.100 millones de dólares) y por la firma del Plan Brady (2.300 millones de dólares) (Damill, Salvatore y Simpson, 2003a). Sin embargo las obligaciones financieras vuelven a aumentar en el primer semestre de 1994, siendo la deuda pública del 29,4\% del PIB en 1993 y del 53,7\% en $2001^{17}$ ¿Por qué crece la deuda pública? La necesidad de financiación por parte del Estado está directamente relacionada con dos factores: la reducción de los ingresos que representa la privatización de los fondos de jubilación y pensión, y la tendencia creciente que siguen el pago de intereses de la deuda fiscal (Damill, Salvatore y Simpson, 2003a, Rapoport, 2000 y Basualdo, 2006). Si bien es cierto que la privatización del sistema previsional fue un duro golpe para las finanzas del Estado, los recortes en sueldos y salarios, gastos operativos e inversiones públicas y

\footnotetext{
${ }^{16}$ A medida que avanza la década, aumenta el riesgo percibido por los tenedores de deuda, por lo que el atractivo para asumirlo debe ser cada vez más alto. Los tipos de interés se mantienen elevados, no sólo por la necesidad de financiación del Estado, sino también por la necesidad de capital extranjero creada por el plan de convertibilidad y su carácter monetario contractivo. Sucede lo contrario a lo que el FMI y BM predecía, la liberalización de capitales no provoca la reducción de los tipos de interés.

${ }^{17}$ Series estadísticas de la CEPAL
} 
Bordón, Marisa. El papel de las finanzas en la dinámica económica argentina entre 1976 y 2001.

la contención de los gastos sociales permitieron un superávit primario, siendo el origen del déficit los gastos financieros.

Una forma de ver la importancia creciente que adquiere la deuda pública es la proporción de ingresos corrientes que financian intereses. Según datos del MECON en 1993 los intereses de la deuda representaban el 10\% de los ingresos corrientes, mientras que en 1998 alcanzaban el 14\% llegando a ser el $28 \%$ en $2001^{18}$.

A finales de 1994 se agotaban los activos susceptibles de ser privatizados y la cancelación de obligaciones y el mantenimiento de la cobertura de la base monetaria hacían necesario más endeudamiento a tipos superiores a los internacionales. Ante la imposibilidad de financiar el desequilibrio fiscal con emisión de dinero, el déficit impulsó la toma de nuevos créditos que implicaron intereses más elevados y más déficit (que a su vez elevó más la deuda y los intereses) (Rapoport, 2000). Para tener una idea de estas diferencias en la tabla 3 vemos ejemplos de tipos pagados en el mercado argentino y en Estados Unidos. El crecimiento de la deuda y los desequilibrios en las cuentas externas elevaban el riesgo país, que presionaba todavía más el alza de los tipos de interés.

Tabla 3. Comparativa de tipos de Interés de títulos públicos Argentinos y de EE.UU.

\begin{tabular}{|c|c|c|c|c|}
\hline & Fin 1993 & Fin 1995 & Fin 1996 & Fin 1997 \\
\hline \multicolumn{5}{|c|}{ Tipo de interés de títulos del tesoro EE.UU. } \\
\hline a 1 año & $3,60 \%$ & $7,17 \%$ & $5,14 \%$ & $5,24 \%$ \\
\hline a 5 años & $5,20 \%$ & $7,83 \%$ & $5,38 \%$ & $5,39 \%$ \\
\hline \multicolumn{5}{|c|}{ Tasa interna de retorno de títulos públicos } \\
\hline Bonex 89 & $7,97 \%$ & $11,02 \%$ & $8,91 \%$ & $8,15 \%$ \\
\hline Bocon dólares serie 1 & $8,44 \%$ & $20,77 \%$ & $13,95 \%$ & $9,71 \%$ \\
\hline Bocon pesos serie 1 & $8,13 \%$ & $26,38 \%$ & $10,54 \%$ & $12,05 \%$ \\
\hline
\end{tabular}

En cuanto a los porcentajes sobre el gasto público total, los gastos financieros representaban en 1993 el 6\%, mientras que otras partidas como los gastos públicos en servicios económicos y los gastos sociales representaban el $11 \%$ y el $65 \%$ respectivamente. Lo significativo es que mientras los gastos sociales se redujeron levemente, al final de la década los intereses eran del $15 \%$ del gasto público total y los gastos en servicios económicos del $5 \%{ }^{19}$.

Estos datos dan evidencia de algo que ya fue mencionado en el primer capítulo de este trabajo: la retirada del Estado de la actividad económica como objetivo de las medidas de los años 90. La aplicación del plan de convertibilidad impide la utilización de la política monetaria, las privatizaciones limitan su intervención como motor de la industria y el recorte de ciertos gastos públicos le quitan la posibilidad de intervenir en términos de inversión y de redistribución.

\footnotetext{
${ }^{18}$ En el año 2001 influye también la caída de la recaudación.

${ }^{19}$ Informes anuales del MECON.
} 
Bordón, Marisa. El papel de las finanzas en la dinámica económica argentina entre 1976 y 2001.

En cuanto a su participación directa en los mercados de capitales, los títulos de deuda pública son los activos financieros más importantes en el mercado financiero argentino. Si tenemos en cuenta el volumen de transacciones de los títulos de deuda y de las acciones veremos que el primero es ampliamente superior. Mientras que en 1993 el volumen anual promedio de acciones negociadas era de 60.000 millones de dólares, el volumen de títulos de deuda pública superaba los 230.000 millones de dólares y en 1995 las cifras eran de 32.000 y 218.000 millones de dólares respectivamente, según datos del MECON. En la tabla 4 podemos ver los valores en el caso de volúmenes operados diariamente.

Tabla 4. Volumen operado promedio diario 1994-2001 (millones de dólares)

\begin{tabular}{|l|c|c|c|c|c|c|c|c|}
\hline & $\mathbf{1 9 9 4}$ & $\mathbf{1 9 9 5}$ & $\mathbf{1 9 9 6}$ & $\mathbf{1 9 9 7}$ & $\mathbf{1 9 9 8}$ & $\mathbf{1 9 9 9}$ & $\mathbf{2 0 0 0}$ & $\mathbf{2 0 0 1}$ \\
\hline Acciones & 443,44 & 126,95 & 123,88 & 153,81 & 105 & 36,96 & 24,11 & 17,35 \\
\hline Títulos deuda pública & 54,56 & 264,44 & 518 & 271,1 & 142,61 & 124,28 & 110,92 & 66,51 \\
\hline
\end{tabular}

Fuente: Informe Bursátil 2001 elaborado por el Instituto Argentino de Mercado de Capitales.

La razón de su mayor dinamismo la encontramos en el atractivo de su rentabilidad y en la mayor garantía que significa para los inversores que el emisor sea el Estado en una economía inestable como la argentina.

Este comportamiento del Estado influye en la forma en que las empresas del sector no financiero y del sector financiero actúan en la economía, con importantes consecuencias en el ámbito productivo.

\subsubsection{El sector no financiero}

Desde finales de los años 70 se han producido cambios en el comportamiento de las empresas del sector no financiero. Este nuevo comportamiento se acentúa hacia finales de siglo y consiste en un desvío de parte de los recursos de las empresas hacia la esfera financiera.

Según Firat Demir (2007), en un estudio realizado sobre el sector no financiero en Argentina, México y Turquía ${ }^{20}$, este comportamiento obedecería a dos factores: el encarecimiento del crédito y la apertura comercial. Tal como hemos visto, las diferentes políticas económicas de carácter restrictivo, que tienen como objetivo el control de la inflación, y la necesidad de financiación del Estado han mantenido elevadas las tasas de interés a lo largo del todo el periodo, obstaculizando el acceso al crédito y las inversiones a largo plazo. Según el autor, el crédito bancario al sector privado representaba el $26 \%$ del PIB durante el periodo 1980-1989, mientras que en la década posterior se redujo al $19 \%$ del PIB. Por su lado, la apertura comercial junto con otros elementos ${ }^{21}$ ha contribuido a la pérdida de rentabilidad de los sectores no financieros (excepto en el caso de las empresas de servicios privatizadas). Además, la apreciación de la moneda llevó a un cambio en los precios relativos en contra de los bienes transables y provocó un estrechamiento en la rentabilidad del sector real, que ayuda a explicar la caída del ahorro y la contracción del empleo. El resultado ha

\footnotetext{
${ }^{20}$ El estudio de Demir se basa en una muestra de 65 firmas que cotizan en bolsa (51 manufactureras, 4 de la construcción, 4 mineras y 6 de generación y distribución de energía eléctrica).

${ }^{21}$ Otro elemento puede ser el aumento de las tarifas públicas, resultado de las privatizaciones, que ha perjudicado al sector productivo elevando sus costes. (Azpiazu y Basualdo, 2004)
} 
Bordón, Marisa. El papel de las finanzas en la dinámica económica argentina entre 1976 y 2001.

sido un desvío de recursos de capital hacia inversiones a corto plazo en el ámbito financiero, cuya rentabilidad resulta más elevada y su riesgo es percibido como menor que el de las inversiones en la actividad productiva a largo plazo (Demir, 2007).

Comprobando los datos de rentabilidad del sector no financiero, medida como la utilidad sobre las ventas, vemos que cae del 5,8\% en 1995 al 2,4\% en el 2000 . Pero debemos diferenciar entre las empresas privatizadas, las vinculadas a éstas y las no vinculadas, Mientras que las primeras tienen una rentabilidad de alrededor del $10 \%$ entre 1994 y 2000, las vinculadas elevan la suya de 5,3\% en 1994 al 6,7\% en el 2000. No obstante, en las no vinculadas la rentabilidad cae del 4,1\% en 1994 a tasas negativas del 0,3\% en 1999 y 1,2\% en 2000 (Montanyà, 2009: 76).

Un elemento que contribuye a la percepción de elevado riesgo de las inversiones productivas es la situación de inestabilidad económica del país en su historia más reciente. Este riesgo y la incertidumbre cada vez mayores, al que se le suman las imperfecciones del mercado, las altas tasas de interés y las crecientes tasas de rentabilidad de los mercados financieros, pueden alentar las inversiones financieras en el corto plazo sobre las inversiones fijas en el largo plazo, contribuyendo a la desindustrialización de la economía (Demir, 2007). Tal como se verifica en la encuesta a las 500 grandes empresas ${ }^{22}$ del INDEC, si bien la inversión bruta fija de estas empresas ha crecido, su participación en los beneficios de explotación ha seguido una tendencia decreciente, como se observa en el gráfico 1. La tendencia se acentúa si se resta el efecto de las amortizaciones.

\section{Gráfico 1. Proporción de la inversión bruta y neta interna sobre los beneficios brutos de explotación. (1993 - 2003)}

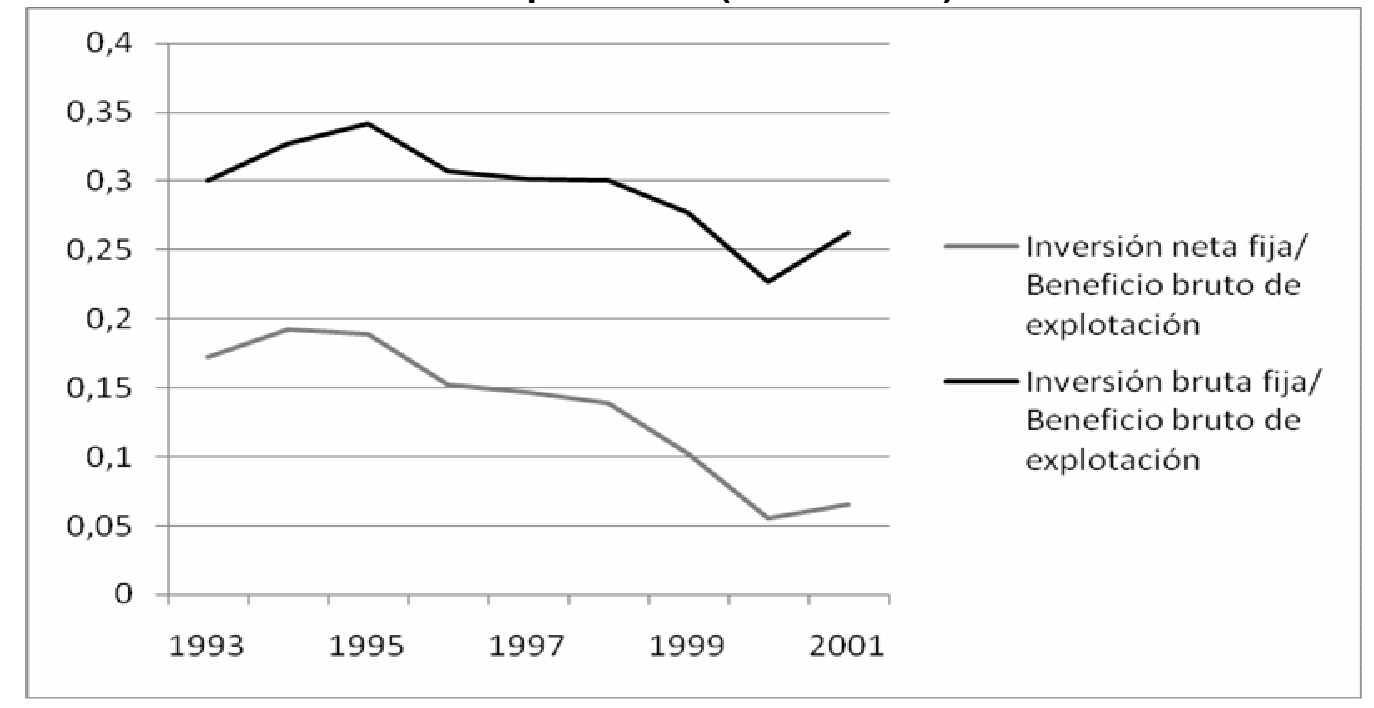

Fuente: Elaboración propia a partir de Encuesta de Grande Empresas del INDEC.

Según Demir es el comportamiento de los capitales extranjeros el que, de alguna forma, también influencia las decisiones de inversión en el corto plazo del sector no

\footnotetext{
${ }^{22}$ La ENGE incluye empresas dedicada a la minería, industria manufacturera, electricidad, gas y agua, construcción, comercio, transporte, comunicaciones y otros servicios. No incluye empresas agropecuarias.
} 
Bordón, Marisa. El papel de las finanzas en la dinámica económica argentina entre 1976 y 2001.

financiero. Estos capitales, como veremos más adelante, entran a la economía por las ganancias procedentes del diferencial de tipo de interés, que para el periodo 1991-2005 han sido en promedio del 9\%. Este diferencial puede ser una de las razones para que las empresas del sector real y financieras inviertan en activos de corto plazo, especialmente en títulos de deuda del gobierno de forma directa, a través de bancos intermediarios, o incluso utilizando el endeudamiento en el exterior (Demir, 2007: 9).

No obstante, no todas las empresas acceden a las inversiones a corto plazo, sólo un número reducido lo hacen, correspondiente a las grandes empresas, los grupos económicos locales, las transnacionales y las empresas de servicios privatizadas.

Pero la forma en que las empresas intervienen en los mercados financieros no se reduce a la compra de títulos de deuda pública o a la compra de otros activos financieros en los mercados locales. Algunas consiguen financiación mediante la emisión de obligaciones en los mercados internacionales, o aprovechan el acceso a créditos internacionales a tipos de interés reducidos para realizar inversiones especulativas en el ámbito local o en los mercados internacionales, si bien parte de estos recursos también son invertidos en actividad productiva (Basualdo, 2003). El endeudamiento privado con bancos internacionales crece a una tasa del $24 \%$ entre el año 1992 y 1999, mientras que la emisión de obligaciones en el exterior lo hace a una tasa del $34 \%$ en el mismo periodo. Ambas suman el $70 \%$ del total del endeudamiento externo del sector no financiero en 1999 que crece durante todo el periodo a una tasa del $27 \%$, lo que resulta significativo si la comparamos con la del sector financiero, que sólo lo hace en un $17 \%{ }^{23}$.

Gráfico 2. Intereses netos sobre beneficios. 500 grandes empresas.

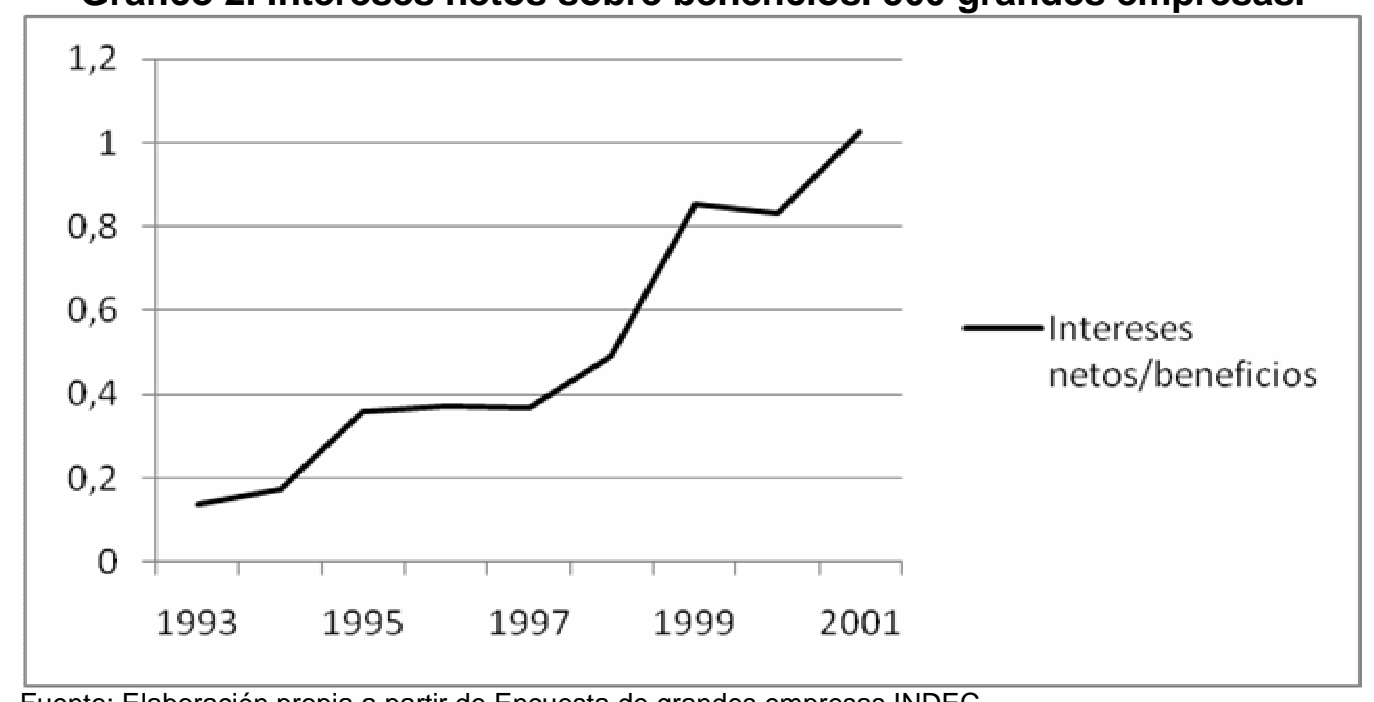

Fuente: Elaboración propia a partir de Encuesta de grandes empresas INDEC.

Otra forma de ver la importancia que van adquiriendo las finanzas en estas empresas es la tendencia creciente que siguen sus gastos financieros como se evidencia en el gráfico 2.

${ }^{23}$ Datos obtenidos del Estadísticas de deuda externa por sectores del INDEC. 
Bordón, Marisa. El papel de las finanzas en la dinámica económica argentina entre 1976 y 2001.

Del mismo modo resulta relevante la inversión en activos financieros en el exterior del sector no financiero. Si analizamos los datos de la tabla 5 las tenencias de activos se concentran en inversiones a corto plazo, aunque las inversiones directas crecen a una tasa mayor.

Varios autores han mencionado que las privatizaciones han sido un factor importante en el papel creciente de las finanzas. Por un lado, algunos de los consorcios que participan en las privatizaciones financian parte de su compra a través de la emisión de obligaciones por parte de las empresas recién adquiridas (Thwaites, 2003). Este comportamiento se extiende a lo largo de la década: en 1993 las empresas de servicios emitían el 57\% (800 millones de dólares) de las obligaciones negociables, en 1995 las empresas que más emiten son las dedicadas a los servicios y al petróleo, 23,8\% y 50,8\% (429 y 915 millones de dólares) y en 1997 los servicios vuelven a liderar las emisiones con el 40,8\% (3.289 millones de dólares) del total de obligaciones negociables (Basualdo, 2003: 229).

Tabla 5. Activos externos del Sector no Financiero. (Saldos a valores de mercado a fin de período en millones de dólares)

\begin{tabular}{|l|c|c|c|c|c|c|c|c|c|cc|}
\hline & dic-91 & dic-92 & dic-93 & dic-94 & dic-95 & dic-96 & dic-97 & dic-98 & dic-99 & dic-00 & dic-01 \\
\hline $\begin{array}{l}\text { S. Privado no } \\
\text { Financiero }\end{array}$ & $\mathbf{5 0 . 0 6 3}$ & $\mathbf{5 0 . 7 6 8}$ & $\mathbf{5 6 . 1 8 2}$ & $\mathbf{5 7 . 8 5 9}$ & $\mathbf{6 9 . 3 1 4}$ & $\mathbf{7 6 . 5 6 7}$ & $\mathbf{8 3 . 8 7 2}$ & $\mathbf{8 9 . 5 4 9}$ & $\mathbf{9 7 . 0 0 3}$ & $\mathbf{9 8 . 7 1 4}$ & $\mathbf{1 0 1 . 4 3 7}$ \\
\hline $\begin{array}{l}\text { Inversión } \\
\text { directa }\end{array}$ & 5.179 & 6.411 & 7.165 & 8.042 & 9.460 & 10.908 & 14.541 & 16.883 & 18.483 & 19.276 & 19.562 \\
Inmobiliaria & 4.280 & 4.524 & 4.787 & 5.096 & 5.358 & 5.589 & 5.731 & 5.840 & 6.001 & 6.210 & 6.257 \\
Otras en emp. & 899 & 1.887 & 2.378 & 2.946 & 4.102 & 5.319 & 8.810 & 11.043 & 12.482 & 13.066 & 13.305 \\
Depósitos & 17.119 & 15.304 & 14.612 & 15.912 & 19.002 & 20.566 & 21.154 & 21.762 & 22.918 & 22.884 & 24.852 \\
$\begin{array}{l}\text { Activos/renta } \\
\begin{array}{l}\text { Activos sin } \\
\text { renta (1) }\end{array}\end{array} 16.656$ & 16.551 & 19.876 & 17.720 & 21.153 & 24.911 & 27.177 & 29.296 & 33.250 & 35.352 & 25.239 \\
\end{tabular}

(1) Están compuestos por tenencia de dólares.

Fuente: Cuenta de Capital Financiera del INDEC.

Finalmente, algunos autores afirman que la venta que los grupos económicos realizan de sus participaciones en las empresas privatizadas se convierten en flujos que se destinan a la inversión en actividades vinculadas a sectores agroexportadores y al ámbito financiero nacional e internacional (Basualdo, 2006 y Azpiazu, 2002).

\subsubsection{El sector financiero: bancos y AFJP}

Desde la reforma de 1977 el acceso al crédito ha sido uno de los obstáculos con los que se han encontrado las empresas para llevar adelante inversiones a largo plazo; factor que ha condicionado su comportamiento, según se ha comentado en el apartado anterior.

La liberalización de los años 90 permitió que algunas empresas pudieran acceder al crédito internacional a través de líneas de financiación de las casas matrices o 
Bordón, Marisa. El papel de las finanzas en la dinámica económica argentina entre 1976 y 2001.

emitiendo obligaciones en los mercados internacionales. No obstante, los bancos argentinos también tuvieron acceso a estos capitales lo que contribuyó a que se otorgaran más créditos (sobre todo en los tempranos 90), un mayor control de la inflación y el aumento de los depósitos (Damill, Salvatore y Simpson, 2003b). Pero la mayoría de los sectores siguió sufriendo restricciones de crédito, recurriendo a recursos internos o préstamos a corto plazo para financiarse, aunque la liberalización comercial redujo las posibilidades de autofinanciación de algunos sectores, presionando los precios a la baja. (Basualdo, 2006).

A lo largo de la década se produjeron numerosos cambios en la estructura del sector financiero. En 1991 el "Decreto de Desregulación" suprime el impuesto sobre la transferencia de valores, se desregulan las comisiones de los operadores de bolsa y se incentiva la cotización de nuevas empresas (Damill, Salvatore y Simpson, 2003b). Además se cambia la ley de Entidades financieras, otorgándose igual tratamiento a los bancos extranjeros respecto de los nacionales, que se complementa con la eliminación del bloqueo a la entrada de nuevas instituciones al sistema financiero en 1993. Al año siguiente entra en vigencia la reforma previsional que introduce nuevos actores en el sistema: las AFJP.

La crisis del "efecto tequila" en 1995, puso de manifiesto la fragilidad del sistema bancario (resultado de la liberalización y de los tipos de interés elevados) y llevó al cierre de entidades financiera ${ }^{24}$ contribuyendo a un aumento de la concentración y de la presencia extranjera.

El acceso a fondos extranjeros de los bancos internacionales presentes en el país les permitía realizar operaciones de arbitraje, financiando operaciones a corto plazo a tipos elevados, con préstamos a largo plazo y a tipos bajos (Damill, Salvatore y Simpson, 2003b).

Tabla 6. Saldos de Valores públicos y préstamos en moneda nacional y extranjera (miles de pesos constantes 1993)

\begin{tabular}{|l|c|c|c|c|}
\hline & $\begin{array}{c}\text { Valores Públicos } \\
\text { Moneda Ext. }\end{array}$ & $\begin{array}{c}\text { Préstamos } \\
\text { Moneda Ext. }\end{array}$ & $\begin{array}{c}\text { Valores Públicos } \\
\text { Moneda Nac. }\end{array}$ & $\begin{array}{c}\text { Préstamos } \\
\text { Moneda Nac. }\end{array}$ \\
\hline $\mathbf{1 9 9 1}$ dic. & 4.426 .842 & 20.696 .612 & 5.502 .253 & 5.416 .949 \\
\hline $\mathbf{1 9 9 2}$ dic. & 3.024 .120 & 12.708 .337 & 2.177 .571 & 3.192 .809 \\
\hline $\mathbf{1 9 9 3}$ dic. & 5.057 .520 & 11.452 .484 & 2.600 .368 & 3.924 .929 \\
\hline $\mathbf{1 9 9 4}$ dic. & 5.885 .502 & 5.980 .372 & 2.462 .901 & 3.812 .884 \\
\hline $\mathbf{1 9 9 5}$ dic. & 8.726 .728 & 8.246 .624 & 1.695 .126 & 4.027 .112 \\
\hline $\mathbf{1 9 9 6}$ dic. & 8.829 .924 & 9.651 .542 & 3.210 .341 & 3.646 .336 \\
\hline $\mathbf{1 9 9 7}$ dic. & 10.402 .269 & 10.252 .338 & 2.716 .140 & 3.597 .912 \\
\hline $\mathbf{1 9 9 8}$ dic. & 10.199 .953 & 13.184 .223 & 2.045 .557 & 3.252 .834 \\
\hline $\mathbf{1 9 9 9}$ dic. & 11.787 .025 & 14.955 .209 & 2.326 .486 & 3.826 .388 \\
\hline $\mathbf{2 0 0 0}$ dic. & 10.331 .617 & 19.512 .547 & 2.131 .718 & 2.656 .039 \\
\hline
\end{tabular}

Fuente: Elaboración propia a partir de Balances consolidados del sistema financiero BCRA.

${ }^{24}$ Entre 1995 y 1999 desaparecieron 85 entidades financieras (Damill, Salvatore y Simpson, 2003b) 
Bordón, Marisa. El papel de las finanzas en la dinámica económica argentina entre 1976 y 2001.

Sin embargo, a pesar de las reformas, los problemas estructurales continuaron. Los altos tipos de interés afectaron fundamentalmente a las Pymes puesto que la aversión al riesgo, sobre todo luego de la crisis de 1995, llevó a los bancos a centrar su actividad en el consumo, el financiamiento de un núcleo de sectores concentrados, grupos económicos y transnacionales (Basualdo, 2003) y sobre todo en la tenencia de activos con bajo riesgo, como los títulos del sector público (Damill, Salvatore y Simpson, 2003b) tal como se comprueba en la tabla 6. Los títulos en moneda nacional siguen un comportamiento similar al de los préstamos en moneda nacional y, curiosamente, sus importes también son similares. En el caso de los títulos en moneda extranjera duplican su importe, mientras que los préstamos se reducen a principio de la década para luego recuperarse, aunque sin llegar al nivel inicial. Tampoco hay una diferencia significativa entre ambos. El sector bancario habría financiado al sector público y al privado en proporciones similares.

En 1998 el endeudamiento interno del sector público con el sistema previsional y los bancos gana peso al manifestarse dificultades en el acceso a la financiación externa (Damill, Salvatore y Simpson, 2003a). La deuda pública interna representa el 7,7\% del PIB en 1994, el 19,4\% en 1998, hasta llegar al 22,3\% en $2001^{25}$.

Con respecto a la reforma previsional configuró un sistema mixto en el cual el trabajador podía elegir si permanecer en el sistema estatal o colocar sus fondos en un sistema de capitalización. En este caso, los fondos serían administrados por las AFJP. Dicha reforma se basaba en los supuestos teóricos del Banco Mundial, que sostenía que el sistema de capitalización mejoraría el sistema financiero, asegurando una mejor intermediación entre ahorro e inversión; los fondos pasarían a formar parte del mercado de capitales que los asignaría eficientemente a las inversiones más rentables.

Las AFJP se convirtieron en una de las fuentes internas más importantes de financiación de deuda pública, puesto que se estableció que el $50 \%$ de los fondos debía invertirse en títulos públicos, lo que permitiría financiar el pago de las jubilaciones en aquel momento (Rapoport, 2000). Las jubilaciones del antiguo sistema se pagarían con aportes de los actuales trabajadores como antes de la reforma, con diferencia de que para ello el Estado debía pagar intereses. A fines del 2001, los títulos del Estado representaban más del $64 \%$ de los fondos, el $13 \%$ eran acciones, el 7\% plazos fijos y el 6\% títulos extranjeros (Di Lorenzo, 2003: 17).

Por otro lado, resultó ser un sistema muy concentrado, en 1997 las administradoras quedaron en manos de unos pocos bancos extranjeros, el 55\% de los fondos pertenecía a BBVA, Citibank, HSBC y Santander (Bellina, 2000: 89) y en el 2000 las 4 administradoras más importantes concentraban el $66 \%$ de los fondos.

El desempeño de los directivos de estas administraciones se medía sobre la base de los resultados en el corto plazo, lo que condujo a que aumentaran las transacciones accionariales y se fomentaran las operaciones basadas en ganancias financieras de corto plazo, en lugar de fomentar la lógica empresarial con horizontes en el largo plazo. La eficiencia de los mercados de capitales no aumentó ya que más del $70 \%$ de los fondos no se dedicó a inversiones en la economía real (Bellina, 2000: 95).

\footnotetext{
${ }^{25}$ Series de estadísticas de la CEPAL.
} 
Bordón, Marisa. El papel de las finanzas en la dinámica económica argentina entre 1976 y 2001.

Las AFJP, como inversores institucionales, dinamizaron la actividad en la esfera financiera incorporando al mercado de títulos públicos y al mercado de valores, aquellos fondos que antes se destinaban al consumo por parte de quienes los percibían. Los activos financieros en manos de dichos inversores siguen una tendencia creciente duplicándose entre 1996 y 2000, hasta superar el 0,3\% del PIB. El sector aumenta su rentabilidad del $0,37 \%$ en 1997 al $5,51 \%$ en $2000^{26}$, ayudada por el peso de las comisiones, que en 2002 representaban 6.262 millones de dólares, de las cuales el $80 \%$ eran ganancias empresarias de un negocio de clientes cautivos $^{27}$ (Di Lorenzo, 2003: 6). Según Basualdo (2006), la reforma del sistema de jubilaciones es una de las formas en las que se traspasaron fondos públicos al sector privado con intenciones de aumentar los espacios de valorización del capital con implicaciones profundas en términos de redistribución ya que limitan los derechos de pensión, reduciendo los salarios indirectos.

Si bien las empresas del sector no financiero, los bancos y los nuevos inversores institucionales locales intervienen en el proceso coadyuvando a la consolidación de las finanzas en el modelo de acumulación que reemplaza a la ISI, el protagonismo del capital extranjero es indiscutible.

\subsubsection{Entrada de capitales extranjeros}

La liberalización y las privatizaciones propiciaron la entrada masiva de capitales, que de acuerdo al discurso de los organismos oficiales, aumentarían la eficiencia en los mercados dirigiéndose hacia las inversiones más rentables con un impacto positivo en el crecimiento de la economía que permitiría el pago de la deuda externa. Por otro lado, estos capitales equilibrarían el déficit de la balanza de pagos producido por el deterioro de la cuenta corriente (Fanelli, Frenkel y Rozenwurcell, 1991), perjudicada por la paridad cambiaria, la apertura comercial y el comportamiento de las empresas transnacionales.

Tabla 7. Necesidades de financiamiento y fuentes (millones de dólares)

\begin{tabular}{|c|l|c|}
\hline & \multicolumn{1}{|c|}{ Valores acumulados } & $\mathbf{1 9 9 2 - 2 0 0 0}$ \\
\hline 1 & Déficit por cuenta corriente & 84248 \\
3 & Variación de reservas & 19268 \\
4 & Variación de activos externos Sector Financiero & 13583 \\
\hline $5=1+2+3+4$ & Variación de activos externos Sector Privado no Financiero & 38666 \\
\hline 6 & IED más inversiones de cartera en acciones & 155764 \\
\hline $7=5-6$ & Necesidades de financiamiento netas & 72671 \\
\hline 8 & Variaciones de deuda externa bruta total & 83093 \\
\hline $9=8-7$ & Diferencia & 85241 \\
\hline
\end{tabular}

Fuente: En "Diagnóstico y perspectivas del sistema financiero argentino" de Mario Damill (2003)

\footnotetext{
${ }^{26}$ Medida como beneficios de explotación sobre stock de capital del año anterior. Datos obtenidos del informe "El caso del Subsector Administradoras de Fondos de Jubilaciones y Pensiones" elaborado por el Grupo Intersecretarial de Trabajo de Cuentas Nacionales del MECON.

${ }_{27}$ Estas comisiones resultaban totalmente regresivas, ya que se trataba de un importe fijo sobre el salario del contribuyente, por lo que los salarios más bajos pagaban una proporción mayor.
} 
Bordón, Marisa. El papel de las finanzas en la dinámica económica argentina entre 1976 y 2001.

No obstante, desde el análisis empírico hay razones para poner en duda si estas eran las razones genuinas para alentar la entrada de capitales extranjeros en la economía argentina. Tal como se aprecia en la tabla 7 , el déficit comercial entre 1992 y 2000 representaba el 54\% del total de las necesidades de financiación. Pero hay dos elementos que resultan significativos: uno es que la variación de los activos externos del sector privado no financiero era el $47 \%$, y el otro, que las necesidades de financiación netas (restando la IED y las inversiones en cartera) eran similares a las variaciones de la deuda externa.

Es decir, que las entradas de capital estarían financiando, de forma significativa, la tenencia de activos externos del sector no financiero en el exterior y la deuda sería el flujo de capitales que compensaría el desequilibrio de las necesidades de financiación.

Por otro lado, la tabla 8 nos muestra la cuenta corriente y la cuenta de capital de la balanza de pagos y nos permite constatar que la diferencia entre ambas es negativa para el sector privado, y positiva para el sector estatal. Se puede inferir que es el superávit de este último el que financia los desequilibrios en las cuentas externas del sector privado y el que sostiene el régimen de convertibilidad, constituyendo la reserva de divisas (Basualdo, 2006).

Tabla 8. Cuenta corriente y cuenta de capitales por sectores 1991-2001 (millones de dólares)

\begin{tabular}{|l|c|c|c|}
\hline & Saldo Público y BCRA & $\begin{array}{c}\text { Sector financiero y no } \\
\text { financiero }\end{array}$ & Total \\
\hline Cuenta Corriente & -36.881 & -51.733 & -88.614 \\
Cuenta de capitales & 69.979 & 25.664 & 95.642 \\
Endeudamiento externo & 56.465 & 42.771 & 99.236 \\
IED & 10.581 & 65.859 & 76.440 \\
Inversión de cartera & 3.508 & -12.462 & -8.954 \\
Fuga de capitales & 0 & -72.819 & -72.819 \\
Otros flujos & -575 & 1.739 & 1.739 \\
\hline Saldo & 33.098 & -26.070 & 7.028 \\
\hline
\end{tabular}

Fuente: En "Estudios de historia económica argentina" de Eduardo Basualdo (2006)

Durante la primera etapa de la convertibilidad el sector privado aportó casi el $60 \%$ a la variación de reservas, pero a partir del 1994 comienza a ser negativa. Entre 1992 y 2002 la contribución del sector público fue de 32.000 millones de dólares y la del sector privado resultó negativa de casi 9.000 millones; es decir que a partir de la segunda mitad de la década el funcionamiento macroeconómico se hizo más "dependiente de la generación de divisas por parte del sector público, a través de la colocación de deuda en los mercados internacionales" (Damill, Salvatore y Simpson, 2003ㄹ. 28).

De lo anterior podemos concluir que la entrada de capitales no tiene como fin exclusivo la financiación del déficit comercial y que el destinatario de dicha financiación es el sector privado de la economía. 
Bordón, Marisa. El papel de las finanzas en la dinámica económica argentina entre 1976 y 2001.

Este mayor ingreso de capital hacia el sector privado se debe, principalmente al proceso de privatizaciones que atrajo $\operatorname{IED}^{28}$ e inversiones de cartera, pero a partir de la crisis de finales de 1994, los ingresos hacia el sector público comenzaron a adquirir importancia. Este hecho puede observarse en los siguientes datos de la cuenta de capital y financiera por sectores: en 1992 los saldos eran 1.226, 1.016 y 6.693 millones de dólares para el sector público, el sector financiero y el sector no financiero respectivamente. En 1995 estos saldos pasan a ser 7.762, 2.769 y -3.322 millones de dólares, finalizando el periodo en 2001 con los siguientes saldos: 7.304, 848 y -13.727 millones de dólares, siguiendo el orden de sectores antes mencionado (Damill, Salvatore y Simpson, 2003 a: 27).

Teniendo en cuenta lo anterior, el Estado habría contribuido a la creación de reservas y a financiar el déficit externo del sector privado, principalmente determinado por la salida de capitales, mediante su endeudamiento. La deuda externa otorgaría a los grupos económicos y a los acreedores internacionales las divisas necesarias para remitir al exterior. Como prueba de ello, Basualdo (2006: 327) otorga algunos elementos al análisis como, por ejemplo, que el endeudamiento de la época es un 58\% mayor que el pago de los intereses devengados (56.465 versus 35.820 millones de dólares) y teniendo en cuenta que el gasto público se recorta y que el déficit público está principalmente explicado por el pago del servicio de la deuda, es plausible pensar que parte de la deuda pública haya financiado la salida de capitales al exterior de los sectores privados.

Como hemos visto, la deuda pública es un destino fundamental de inversión de capitales foráneos, una medida aproximada de su importancia es el monto de deuda externa pública sin los préstamos de los organismos internacionales y acreedores oficiales. Aunque la presencia de capitales extranjeros va menguando a partir de 1998, este monto aumenta de 19.023 a 56.655 millones de dólares entre 1992 y 2000 , pasando a representar del $33 \%$ al $70 \%$ del total de la deuda externa pública. Es decir, que una parte muy importante de la deuda pública está financiada por el sector externo privado. En cuanto a la tenencia extranjera de bonos y títulos públicos crece un 38\% entre 1992 y 1998 pasando de 7.690 a 53.488 millones de dólares. Su importancia como componente también crece, mientras que en 1992 representaba el $13,5 \%$ del total de la deuda externa, en 1998 alcanzaba el $67 \%{ }^{29}$.

Para completar este análisis vemos que los capitales que se dirigen a IED entre 1992 y 1998 alcanzan un monto de 42.252 millones de dólares, un monto mayor que las inversiones en cartera que fueron de 8.589 millones de dólares (Kulfas, Porta y Ramos, 2002: 22). Sin embargo, las primeras crecen a un $7 \%$ durante este periodo, al tiempo que las inversiones en cartera lo hacen en un 10,4\%. Es preciso tener en cuenta que la IED que ingresa en los 90 se dirige principalmente a la compra de activos ya existentes, por lo que reduce su impacto en la economía real.

Teniendo en cuenta lo analizado en este apartado la contribución del ahorro externo a la economía real resulta, por lo menos, cuestionable. Veamos de qué manera los comportamientos descritos del Estado, del los sectores privados y del ahorro externo se cristalizan en la dinámica económica.

\footnotetext{
${ }^{28}$ Parte de estas inversiones son capitales repatriados que buscan participar del gran negocio que suponen las privatizaciones (Basualdo, 2006)

${ }^{29}$ Datos obtenidos de la estimación de la deuda externa por sector residente del INDEC.
} 
Bordón, Marisa. El papel de las finanzas en la dinámica económica argentina entre 1976 y 2001.

\subsection{Lógica de funcionamiento. Las finanzas como centro de gravitación}

En la primera parte de este trabajo hemos hecho un resumen de las diferentes políticas económicas que han contribuido modificar la lógica de funcionamiento de la economía hacia una nueva lógica que gravita alrededor de las finanzas, así como sus principales rasgos, en la segunda parte hemos abordado el comportamiento de los sujetos que se encuentran en el centro de esta lógica y en esta sección analizaremos las relaciones de dichos sujetos que le dan coherencia.

A comienzos de los 90, en el marco de las medidas de ajuste del FMl y BM para la renegociación de la deuda externa, Argentina se encuentra en una situación de crisis profunda a causa de la hiperinflación, la quiebra del Estado, la recesión económica y el crecimiento del desempleo. La adopción de estas medidas llevaría al país hacia el equilibrio macroeconómico, el crecimiento y el pago de la deuda. Sin embargo estos no fueron los resultados obtenidos; como es sabido Argentina sufre, a finales del 2001, una de sus mayores crisis, para algunos un adelanto de lo que se avecinaba a escala mundial 7 años después.

Al contrario de lo esperado deuda pública crece, y es junto a las políticas económicas uno de los elementos a través del cual el Estado contribuye a la nueva dinámica de funcionamiento de la economía, en la que las finanzas aumentan su protagonismo.

\section{Gráfico 3. Promedio mensual en porcentaje nominal anual de diferentes tipos de} interés.

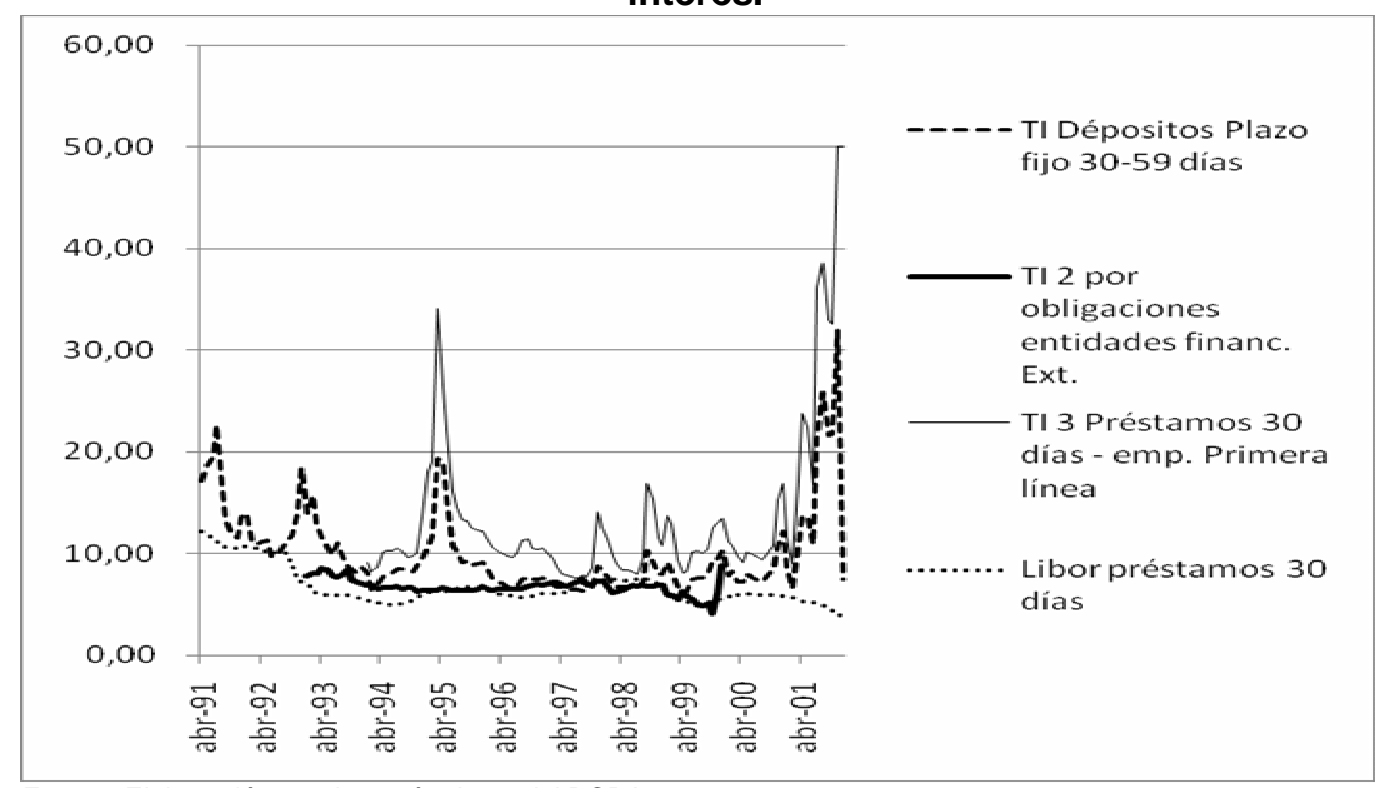

Fuente: Elaboración propia según datos del BCRA.

La necesidad de financiación del Estado mantiene elevados los tipos de interés, lo que eleva las rentabilidades en el ámbito financiero desviando parte de los recursos fuera del circuito de la economía real. El diferencial entre los tipos de interés local y los internacionales, junto con las altas rentabilidades en algunos sectores, se convierte en un poderoso factor de atracción de capitales extranjeros a corto plazo. Tal como vemos en el gráfico 3 los tipos interés nacionales resultan bastante más elevados que el LIBOR y los tipos que pagan las empresas por la colocación de 
Bordón, Marisa. El papel de las finanzas en la dinámica económica argentina entre 1976 y 2001.

obligaciones en entidades financieras internacionales. Puede observarse, también, cómo en momentos de crisis (1995, 1998 y finales de la década) ante la posibilidad de que dejen de entrar capitales o se produzca una salida masiva, los tipos se elevan aún más. En 2001 el tipo de interés real llegó al 23\%.

Pero estos elevados tipos de interés dificultan las inversiones en proyectos a largo plazo al encarecer la financiación. Esta distorsión en el acceso al crédito comienza a manifestarse desde la reforma financiera de 1977 y se complementa con las medidas de apertura del mercado de bienes y servicios tomadas desde entonces, que afectan a las rentabilidades de las actividades productivas, realzando el atractivo de las inversiones financieras.

Las empresas del sector no financiero, especialmente las grandes empresas, desvían parte de sus recursos hacia las inversiones de carácter especulativo, y la distorsión se mantiene a través del tiempo, puesto que los bancos perciben más riesgoso el crédito a las empresas que la financiación al sector público, por lo que también terminan participando del proceso.

Esta situación se manifiesta en la evolución que sigue la inversión en la economía como porcentaje del PIB entre 1970 y 2001, como puede apreciarse en el gráfico 4. Si bien la evolución no es uniforme, sigue una tendencia decreciente y no recupera los niveles de principio de los 70. A comienzos de los años 90 se aprecia una recuperación, previsiblemente por la profundidad de la caída en los años 80 y por el impulso de la estabilidad de los primeros años, pero a finales de la década sigue su camino descendente. Para complementar estos datos la formación bruta de capital crece un $3 \%$ entre 1970 y 1979 , presenta una tasa negativa del 6,7\% entre 1980 y 1989 , y del $1 \%$ entre 1993 y 2001.

Gráfico 4. Participación de la inversión en PIB

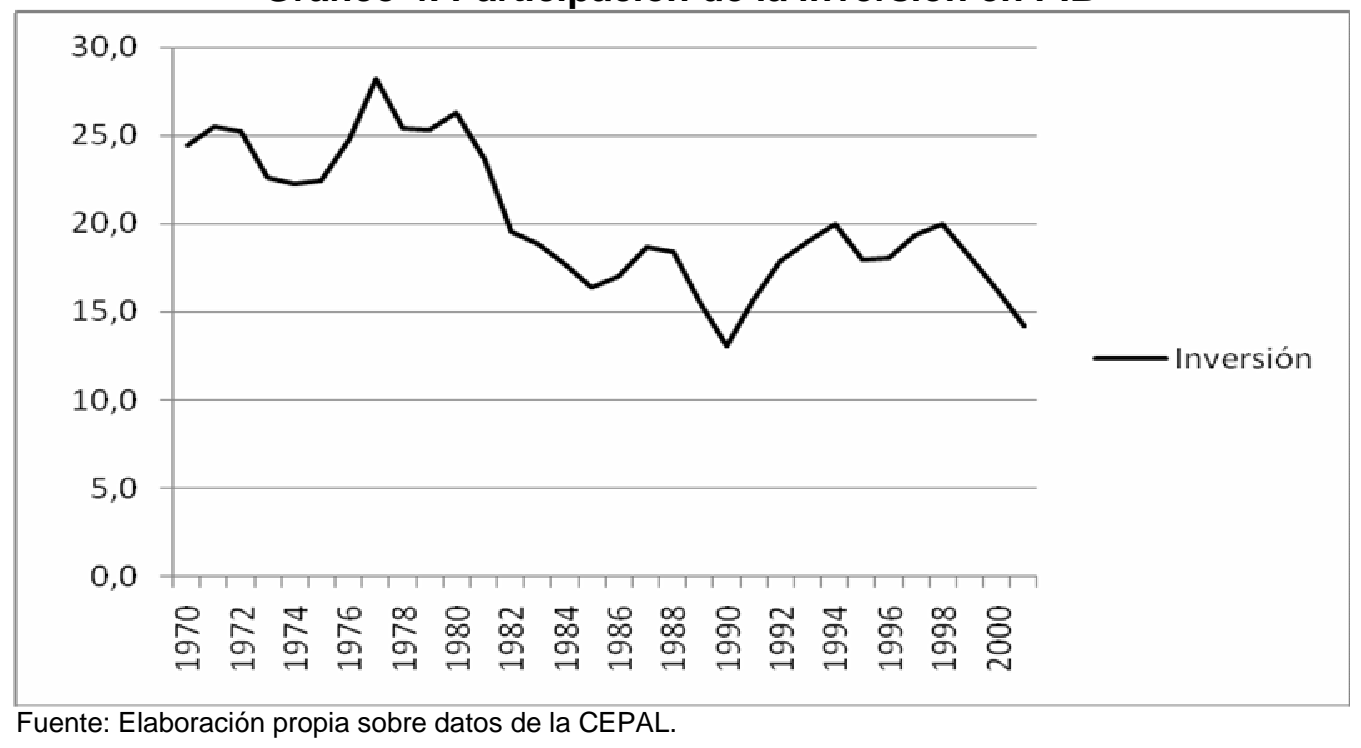

El estancamiento en la inversión afecta al aparato productivo de la economía y al crecimiento, como puede verse en el gráfico 5 el sector manufacturero pierde peso, mientras que el de servicios financieros y a empresas crece. Dentro de este sector el porcentaje de intermediación financiera en el PIB pasa del 5,3\% en 1993 a 9,3\% en 
Bordón, Marisa. El papel de las finanzas en la dinámica económica argentina entre 1976 y 2001.

el 2000. La importancia del sector también se manifiesta en indicadores como la capitalización bursátil respecto de la evolución del PIB; que para acciones y títulos pasa del $12 \%$ en 1992 al $35 \%$ en $1997^{30}$.

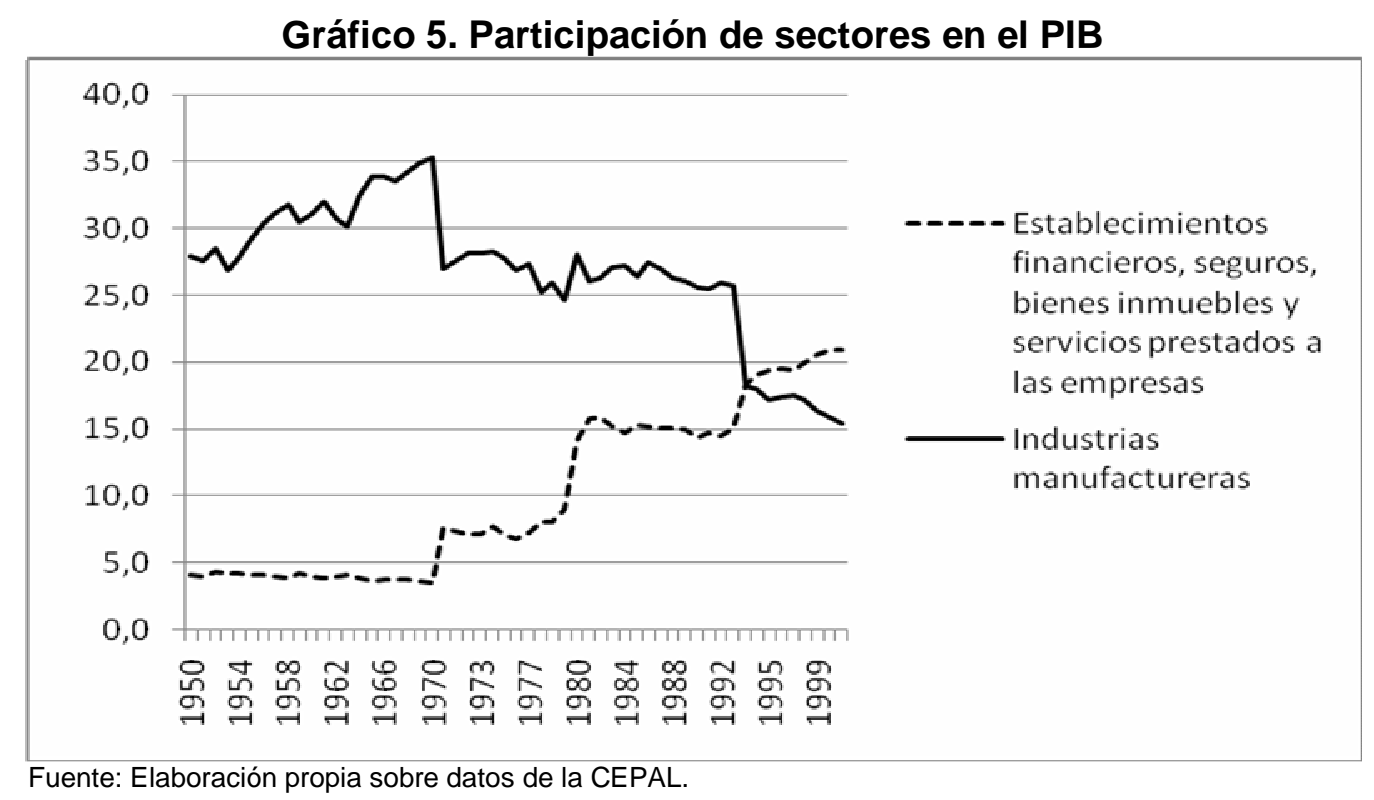

Como resultado, la actividad productiva deja de ser el centro sobre el que gravita la economía, lo que afecta, a su vez, a la inversión y con ello a la redistribución, no sólo por el aumento del desempleo, sino por la reducción de salarios (el salario medio real disminuye en un $27 \%$ entre 1980 y 2000). El salario se convierte en la variable de ajuste, ampliándose el margen de ganancias del capital, permitiendo, a su vez, su apropiación creciente por la fracción financiera. La caída de la participación del salario en el PIB y el aumento del desempleo afectan el consumo interno y acentúan la polarización social.

En el sector externo, el ingreso de capitales extranjeros no se dirige en su mayor parte a la actividad productiva, sino que una proporción importante de los capitales tiene como destino las inversiones financieras. Los capitales financieros internacionales se valorizan en la esfera financiera interna, mayoritariamente comprando deuda pública, la que a su vez compensa los desequilibrios que surgen por la salida de capitales (activos financieros y otras inversiones que las empresas locales tienen fuera del país), ingresa las divisas necesarias para que pueda producirse y mantiene la política monetaria.

Como consecuencia aumenta la dependencia de flujos de capital privado a corto plazo como motor del crecimiento, necesarios para mantener la política económica y el proceso que acabamos de describir. Esta dependencia acentúa las distorsiones existentes ya que, ante la posibilidad de una suspensión en la entrada o una salida masiva de capitales, los tipos de interés vuelven a subir, lo que sigue dificultando el acceso al crédito y sigue haciendo más atractivas las inversiones financieras.

\footnotetext{
${ }^{30}$ Series estadísticas de la CEPAL, informes trimestrales del MECON e INDEC.
} 
Bordón, Marisa. El papel de las finanzas en la dinámica económica argentina entre 1976 y 2001.

Teniendo en cuenta lo analizado hasta ahora el papel de los capitales internacionales es fundamental, parece ser que las finanzas adquieren importancia integrando a la economía argentina al sistema financiero internacional. Esta importancia de la esfera financiera se manifiesta tal como hemos visto en el aumento de peso como sector de la economía, en el aumento de la rentabilidad de los sectores vinculados a él, como las AFJP y las grandes empresas que participan en el proceso.

Lejos de reactivar la inversión en el sector productivo y acelerar el crecimiento, la entrada masiva de capitales externos y los capitales internos parecen dirigirse, en gran medida, hacia otras inversiones, lo que se cristaliza en tasas de crecimiento poco elevadas, tal como se puede observar en la década del 90, cuando la economía creció sólo un 3,3\%.

En resumen, el Estado juega un papel muy importante para la configuración del modelo alternativo a la ISI, y su instrumento fundamental es la deuda pública, que mantiene elevados los tipos de interés, impactando en las rentabilidades financieras, atrayendo capitales nacionales y extranjeros. Estos últimos resultan necesarios para la dinámica económica y para el equilibrio de las variables macroeconómicas fundamentales para mantener la confianza de los inversores y mantener bajo control al conocido fantasma de la inflación. Esta dependencia eleva los tipos de interés atrayendo a más capitales, pero haciendo a la economía más vulnerable a su salida por los efectos del excesivo y costoso endeudamiento. Esta dinámica va alimentando la esfera financiera sobre la que gira la economía, ampliando sus espacios de actuación, aumentando su margen de maniobra, subordinando paradójicamente a la actividad productiva y propiciando cambios estructurales y una grave regresión social.

\section{CONCLUSIONES}

El modelo de acumulación que se ha ido gestando en la Argentina desde mediados de los 70 es resultado de la implementación de políticas económicas de corte neoliberal que a medida que avanzan en su consolidación también contribuyen a acrecentar las contradicciones llevándolo a la crisis a finales del 2001. Las mismas han ido modificando las estructuras y dinámicas de la economía argentina.

A partir de la liberalización, la desregulación de la economía y las privatizaciones los capitales financieros van adquiriendo importancia, ganan espacio, margen de maniobra, consiguen que otras actividades dancen al compás de su lógica.

Su implementación permite la integración a las finanzas internacionales y en base a ella se va desarrollando la lógica de funcionamiento del modelo en el que el capital financiero tiende a ocupar un lugar cada vez más destacado. ¿Que agentes económicos permiten esta expansión? En primer lugar el Estado, que es quien establece las políticas económicas, y que en su afán de no intervención, termina interviniendo aunque en un sentido diferente al del modelo ISI, sin impulsar las actividades productivas y sin intención redistributiva. Su endeudamiento es la cristalización de esa intervención y es la que a su vez alimenta el modelo convirtiendo sus títulos en los activos financieros más destacados. La configuración de un ambiente favorable a esta expansión financiera se va creando, no sólo a 
Bordón, Marisa. El papel de las finanzas en la dinámica económica argentina entre 1976 y 2001.

través de las necesidades de financiación de un Estado cada vez más endeudado, sino también por el comportamiento de los nuevos agentes resultado de las privatizaciones: las AFJP y las empresas privatizadas; y de los viejos agentes: las grandes empresas de grupos económicos locales y conglomerados extranjeros. Pero como dijimos al comienzo de este párrafo la inserción en las finanzas mundiales es el eje fundamental sobre el que gira el modelo, y son los capitales internacionales agentes destacados, ya que son ellos los en busca de rentabilidad llegan a la economía argentina mediante la oferta de préstamos en los años 70 , la imposición de medidas de fondomonetaristas en la crisis del 80 y la entrada masiva de capitales en los 90 .

Una de las consecuencias directas de esta dinámica es la dependencia del ahorro extranjero para el funcionamiento de la economía, que la vuelve vulnerable por las consecuencias que puede tener la salida masiva de capitales.

Por otro lado la expansión de la esfera financiera tiene su contracara en la actividad productiva, ya que las inversiones especulativas resultan más rentables que las productivas con graves consecuencias en términos de empleo y crecimiento. La dependencia de los capitales extranjeros y su vulnerabilidad afectan al crecimiento que no sólo es modesto sino también volátil.

Las consecuencias en el sector real contribuyen a la configuración del nuevo patrón de especialización agroexportador, en el que también influye la pérdida de importancia de la demanda interna. Esta caída de la demanda no sólo se debe a inversión, sino también al consumo; al que también afecta este modelo en el que las finanzas toman un papel central. Las medidas de desregulación del mercado laboral, el terreno que se pierde en la dictadura en términos de organizaciones sociales y de derechos, el remante final en la década del 90 con la privatización del sistema de pensiones, tienen como resultado el aumento del desempleo, la precarización laboral y un aumento de la desigualdad. Los impactos en la redistribución también se deben a los procesos inflacionarios y los conflictos entre las distintas fracciones de capital. Como resultado el salario pierde participación, el capital gana margen y la actividad financiera se alimenta de este mayor margen, ampliándolo a través del desvío de inversiones productivas, eliminando de esta forma los efectos que ellas podrían tener en términos de empleo. Todo esto tiene su manifestación más clara en las enormes bolsas de pobreza, la marginación social y económica de miles de personas que en 2002 representaban un porcentaje muy importante de la población. ¿Es viable en el orden de cosas que acabamos de describir un proyecto de desarrollo económico que intente solucionar problemas de inclusión social o mejora de condiciones de vida de la población? ¿Cuáles son los límites que puede soportar una sociedad golpeada tan brutalmente por la dinámica económica? Son algunas de los planteamientos que surgen desde el análisis realizado en este trabajo.

Por otro lado, el mismo puede ser el punto de partida para trabajos posteriores que aborden el papel del sector financiero después de la crisis, y el lugar que ocupan en él la deuda pública y los capitales extranjeros. Otros estudios a realizar podrían tener como objeto los motores de la recuperación del crecimiento económico y su alcance; ya que aunque se han producido algunas modificaciones, a la luz de los hechos no parecen proyectarse en el plano social, la polarización no ha cedido y las soluciones en términos de aumento de salarios y asistencialismo se convierten en parches 
Bordón, Marisa. El papel de las finanzas en la dinámica económica argentina entre 1976 y 2001.

temporales. La tendencia agroexportadora va ganando terreno y sus vínculos con los mercados financieros puede ser otro de los objetos de investigación para los cuales este trabajo puede servir de guía.

Aunque algunos indicadores hayan mejorado hay indicios de que los cambios no han sido radicales. ¿Hasta qué punto las estructuras cimentadas durante el periodo estudiado siguen vigentes? La fortaleza de su arraigo y las dimensiones de los cambios producidos en este periodo nos hace pensar que la respuesta a esta pregunta es afirmativa. Siendo así, podría volver a producirse una situación similar a la que surge después de 1976 y se consolida en los años 90, aunque existen otros elementos a tener en cuenta, sobre todo el papel del nuevo socio comercial, China, y los potenciales alcances de la actual crisis de los países desarrollados, que no pueden subestimarse aunque de momento hayan tenido un impacto reducido. 
Bordón, Marisa. El papel de las finanzas en la dinámica económica argentina entre 1976 y 2001.

\section{BIBLIOGRAFÍA}

Arrizabalo, X. (Ed.) (1997): Crisis y ajuste en la economía mundial. Las implicaciones y el significado de las políticas del FMI y el BM, Síntesis, Madrid.

Azpiazu, D. (2002): "Privatizaciones, rentas de privilegio, subordinación estatal y acumulación del capital en la Argentina contemporánea" en Azpiazu, D. y Schorr M.: Privatizaciones, rentas de privilegio, subordinación estatal y acumulación del capital en la Argentina contemporánea, FLACSO, Facultad Latinoamericana de Ciencias Sociales, Sede Argentina, Extraído el 11 de Julio de 2010 de:

http://bibliotecavirtual.clacso.org.ar/ar/libros/argentina/flacso/no3_Privatizaciones Argentinas90CTA.pdf

Azpiazu, D. y Basualdo, E. (2004): Las privatizaciones en la Argentina. Génesis, desarrollo y principales impactos estructurales, FLACSO, Facultad Latinoamericana de Ciencias Sociales. Sede Argentina. Extraído el 1 de Noviembre de 2009 de:

http://bibliotecavirtual.clacso.org.ar/ar/libros/argentina/flacso/azpiazu.pdf

Basualdo, E. (1987): Deuda externa y poder económico en la Argentina, Nueva América, Buenos Aires.

Basualdo, E. (2003): Concentración y centralización del capital en la Argentina durante la década del noventa, Universidad Nacional del Quilmes, Buenos Aires, (1⿳亠丷厂 ed. 2000)

Basualdo, E. y Kulfas, M. (2000): "Fuga de capitales y endeudamiento externo en la Argentina", Realidad Económica, no 73, Julio-Agosto de 2000, pp. 73-106.

Basualdo, E. (2006): Estudios de historia económica argentina. Desde mediados del siglo XX a la actualidad, Siglo XXI, Buenos Aires.

Basualdo, E. (2009): "Evolución de la economía argentina en el marco de las transformaciones de la economía internacional de las últimas décadas" en Arceo, E. et al.: Los condicionantes de la crisis en América Latina. Inserción internacional y modalidades de acumulación, pp. 321-382, Comisión de Economía, Buenos Aires.

Bellina Yrigoyen, J. E. (2000): "Fondos de pensión, mercado de capitales y déficit público", Invenio, v. 3, № 4-5, Diciembre de 2000, pp. 87-96.

Chesnais, F. (2001): "La teoría del régimen de acumulación financiarizado: contenido, alcance e interrogantes", Revista de Economía Crítica, no1, Abril de 2003, pp. 37-72.

Chesnais, F. (2001b): La mundialización financiera: génesis, costos y desafíos, Losada, Buenos Aires.

Chesnais, F. (2003): "¿Crisis financieras 0 indicios de crisis económicas características del régimen de acumulación actual?" en Chesnais, F. y Plihon, D.: Las trampas de las finanzas mundiales: diagnósticos y remedios, pp. 41-57, Akal, Madrid.

Comisión Económica para América Latina (2000): Anuario Estadístico de América Latina y el Caribe 2000, Santiago de Chile, Extraído en 15 de Junio de 2010 de http://www.eclac.org/publicaciones/xml/8/6228/c-2-XI.pdf

Comisión Económica para América Latina (2009): Anuario Estadístico de América Latina y el Caribe 2009, Santiago de Chile, Extraído en 15 de Junio de 2010 http://www.eclac.org/publicaciones/xml/9/38409/LCG2430b_1.pdf

Damill, M., Salvatore, N. y Simpson, L. (2003a): Diagnóstico y perspectivas del sistema financiero argentino. I) Las relaciones financieras en la economía 
Bordón, Marisa. El papel de las finanzas en la dinámica económica argentina entre 1976 y 2001.

argentina en los años 90. Centro de Estudios de la Situación y Perspectivas de la Argentina, Universidad de Buenos Aires, Febrero de 2004, Buenos Aires.

Damill, M., Salvatore, N. y Simpson L. (2003b): Diagnóstico y perspectivas del sistema financiero argentino. II) El sistema financiero de la Argentina bajo el régimen de convertibilidad y la transición a un nuevo modelo de intermediación. Centro de Estudios de la Situación y Perspectivas de la Argentina, Universidad de Buenos Aires, Febrero de 2004, Buenos Aires.

Demir, F. (2007): Private Investment, Portfolio Choice and Financialization of Real Sector in Emerging. Munich Personal Repec Archive, Working Paper nํ 3835, Noviembre de 2007, Extraído el 25 de Julio de 2010 de: http://mpra.ub.uni-muenchen.de/3835/

Di Lorenzo, J. L. (2003): Mundialización financiera y fondos de pensión: Argentina como caso ejemplar, Instituto para el Modelo Argentino.

Fanelli, J. M., Frenkel y R., Rozenwurcell, G. (1991): "Ahorro, inversión y finaciamiento en Argentina y Filipinas: un análisis comparado", Integración Latinoamericana, v. 16, no 167, pp. 64-89.

Frenkel, R. (1980): "El desarrollo reciente del mercado de capitales en la Argentina", Desarrollo Económico, v.20, no 78, Julio-Septiembre de 1980, pp.215-248.

Gill, L. (2002): Fundamentos y límites del capitalismo, Trotta, Madrid.

Instituto Argentino de Mercado de Capitales (2001): Anuario Bursátil 2001, Extraído el 25 de Julio de 2010 de: http://www.iamc.sba.com.ar/lmgs/Dyn/ArchivosLenguajes/5434-2010-5-28T12-5-0.pdf

Kulfas, M., Porta, F. y Ramos, A. (2002): "Inversión extranjera y empresas transnacionales en la economía argentina", Estudios y Perspectivas, nำ10, CEPAL, Comisión Económica para América Latina sede Buenos Aires.

Ministerio de Economía de La Nación (2001): El caso del Subsector Administradoras de Fondos de Jubilaciones y Pensiones, Extraído el 22 de Julio de 2010 de: http://www.mecon.gov.ar/secpro/dir_cn/afjp.pdf

Montanyà, M. (2009): "Crisis financiera y ajuste salarial en Argentina", en Álvarez Peralta et al.: Ajuste y Salario. Las consecuencias del neoliberalismo en América Latina y Estados Unidos, pp. 53-80, Fondo de Cultura Económica, Madrid.

Neffa, J. C. (1998): Modos de regulación, regímenes de acumulación y sus crisis en Argentina (1880-1996), Eudeba, Buenos Aires.

Palazuelos, E. (2000): Contenido y método de la economía. El análisis de la economía mundial, Akal, Madrid.

Palley, T. I. (2007): Financialization: What it is and Why it Matters, The Levy Economics Institute, Working Paper no 525, Diciembre de 2007, New York.

Rapoport, M. y colaboradores (2000): Historia económica, política y social de la Argentina (1880-2000), Macchi, Buenos Aires.

Salama, P. (2003): "América Latina y Asia: una misma lógica de crisis, pero responsabilidades nacionales específicas" en Chesnais, F. y Plihon, D.: Las trampas de las finanzas mundiales: diagnósticos y remedios, pp. 123-135, Akal, Madrid.

Serfati, C. (2003): "La dominación del capital financiero: ¿qué consecuencias?" en Chesnais, F. y Plihon, D.: Las trampas de las finanzas mundiales: diagnósticos y remedios, pp. 59-72, Akal, Madrid.

Thwaites Rey, M. (2003): La (des)ilusión privatista. El experimento neoliberal en la Argentina, Eudeba, Buenos Aires. 
Bordón, Marisa. El papel de las finanzas en la dinámica económica argentina entre 1976 y 2001.

\section{Fuentes Estadísticas.}

Banco Central de la República Argentina (www.bcra.gov.ar) Comisión Económica para América Latina (www.eclac.org) Instituto Nacional de Estadísticas y Censos (www.indec.gov.ar) Ministerio de Economía de la Nación (www.mecon.gov.ar) 